\title{
Pitchers of Nepenthes khasiana express several digestive-enzyme encoding genes, harbor mostly fungi and probably evolved through changes in the expression of leaf polarity genes
}

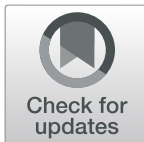

\author{
Jeremy Dkhar ${ }^{1,2^{*}}$ D, Yogendra Kumar Bhaskar ${ }^{3}$, Andrew Lynn $^{3}$ and Ashwani Pareek ${ }^{1}$
}

\begin{abstract}
Background: A structural phenomenon seen in certain lineages of angiosperms that has captivated many scholars including Charles Darwin is the evolution of plant carnivory. Evidently, these structural features collectively termed carnivorous syndrome, evolved to aid nutritional acquisition from attracted, captured and digested prey. We now understand why plant carnivory evolved but how carnivorous plants acquired these attributes remains a mystery. In an attempt to understand the evolution of Nepenthes pitcher and to shed more light on its role in prey digestion, we analyzed the transcriptome data of the highly specialized Nepenthes khasiana leaf comprising the leaf base lamina, tendril and the different parts/zones of the pitcher tube viz. digestive zone, waxy zone and lid.
\end{abstract}

Results: In total, we generated around 262 million high-quality Illumina reads. Reads were pooled, normalized and de novo assembled to generate a reference transcriptome of about 412,224 transcripts. We then estimated transcript abundance along the $N$. khasiana leaf by mapping individual reads from each part/zone to the reference transcriptome. Correlation-based hierarchical clustering analysis of 27,208 commonly expressed genes indicated functional relationship and similar cellular processes underlying the development of the leaf base and the pitcher, thereby implying that the Nepenthes pitcher is indeed a modified leaf. From a list of 2386 differentially expressed genes (DEGs), we identified transcripts encoding key enzymes involved in prey digestion and protection against pathogen attack, some of which are expressed at high levels in the digestive zone. Interestingly, many of these enzyme-encoding genes are also expressed in the unopened N. khasiana pitcher. Transcripts showing homology to both bacteria and fungi were also detected; and in the digestive zone, fungi are more predominant as compared to bacteria. Taking cues from histology and scanning electron microscopy (SEM) photomicrographs, we found altered expressions of key regulatory genes involved in leaf development. Of particular interest, the expression of class III HOMEODOMAIN-LEUCINE ZIPPER (HD-ZIPIII) and ARGONAUTE (AGO) genes were upregulated in the tendril.

\footnotetext{
* Correspondence: jeremydkhar@gmail.com

'Stress Physiology and Molecular Biology Laboratory, School of Life Sciences, Jawaharlal Nehru University, New Delhi 110067, India

${ }^{2}$ Agrotechnology Division, CSIR-Institute of Himalayan Bioresource Technology, Palampur, Himachal Pradesh 176061, India

Full list of author information is available at the end of the article
}

C C The Author(s). 2020 Open Access This article is licensed under a Creative Commons Attribution 4.0 International License, which permits use, sharing, adaptation, distribution and reproduction in any medium or format, as long as you give appropriate credit to the original author(s) and the source, provide a link to the Creative Commons licence, and indicate if changes were made. The images or other third party material in this article are included in the article's Creative Commons. licence, unless indicated otherwise in a credit line to the material. If material is not included in the article's Creative Commons licence and your intended use is not permitted by statutory regulation or exceeds the permitted use, you will need to obtain permission directly from the copyright holder. To view a copy of this licence, visit http://creativecommons.org/licenses/by/4.0/ The Creative Commons Public Domain Dedication waiver (http://creativecommons.org/publicdomain/zero/1.0/) applies to the data made available in this article, unless otherwise stated in a credit line to the data. 
(Continued from previous page)

Conclusions: Our findings suggest that $N$. khasiana pitchers employ a wide range of enzymes for prey digestion and plant defense, harbor microbes and probably evolved through altered expression of leaf polarity genes.

Keywords: Nepenthes khasiana, Leaf transcriptome, Pitcher development and evolution, Prey digestion, Plant defense

\section{Background}

Carnivorous plants are remarkable botanical entities that are of considerable interest in the context of plant adaptation. These plants have evolved several times independently in five angiosperm lineages and are characterized by a set of features termed carnivorous syndrome $[1,2]$. This syndrome is reflected mostly in the leaves to facilitate the attraction, capture and digestion of prey and the subsequent absorption of the dissolved nutrients to offset low nutrient availability in their natural habitat. Among these highly specialized leaves are the pitfall traps or 'pitchers' recognized in three families viz. Cephalotaceae, Nepenthaceae and Sarraceniaceae [3]. Members of the family Sarraceniaceae develop pitchers that function both in prey trapping and photosynthesis whereas Nepenthes and Cephalotus produce pitchers that can capture prey with little or no photosynthesis [4]. However, and unlike pitchers of Sarracenia and Cephalotus, the Nepenthes pitcher is attached at the base via a rigid slender structure called tendril to a flattened photosynthesizing leaf base lamina (Fig. 1). It is further divided into two anatomically and functionally distinct zones: a slippery waxy zone covering the upper inner part of the pitcher that function in prey trapping, and a basal digestive zone entrenched with enzyme secreting glands capable of absorbing the available nutrients (Fig. 1). Covering the mouth of the pitcher is a nectary gland-bearing lid that functions in prey attraction as well as in shielding rainwater from diluting the digestive juice [5]. This extraordinary attribute has fascinated scientists worldwide and research has progressed in the direction of understanding the mechanism of entrapment and digestion.

For elucidating the trapping mechanism of Nepenthes pitchers, studies have focused on the slippery waxy zone [6], the wettable peristome [7-9] and the viscoelastic digestive fluid $[10,11]$. Once trapped inside the fluidcontaining pitcher, insects begin to die and are digested through several hydrolytic enzymes. These enzymes include aspartic or cysteine proteinase, chitinase, ribonuclease, esterase, phosphatase, $\beta$-1,3-glucanase and $\beta$ $D$-xylosidase (Biteau et al. [12] and references therein). But the source of these enzymes remains a debatable question, to date. This situation arises from the contradictory results that showed either presence $[13,14]$ or absence [12, 15] of microbes in the digestive fluids of certain unopened Nepenthes pitchers. Whether $N$. khasiana pitchers harbor microbes are not yet known; however, we do know that it contains genes encoding chitinase enzymes [16] and it produces the antifungal secondary metabolite naphthoquinones [17]. Beyond this, no other report is available on pathogenesis-related or prey digestion genes in N. khasiana. Moreover, whether similar numbers of genes are expressed in both opened and unopened pitchers of Nepenthes remains to be explored.

To address these issues, we carried out a sequencingbased transcriptome profiling of the highly specialized $N$. khasiana leaf comprising the leaf base lamina, tendril and the different parts/zones of the pitcher tube viz. digestive zone, waxy zone and lid. Our analysis of the transcriptome data suggests that the Nepenthes pitcher is indeed a modified leaf. This is based on the observation that in comparison to the tendril, the leaf base lamina shares similar transcript expression patterns with the different parts/ zones of the pitcher tube. We found that in the presence of captured prey or pathogenic microbes (open pitcher), almost all transcripts encoding key enzymes known to play a role in prey digestion and protection against pathogen attack are expressed in the $N$. khasiana pitcher. Unexpectedly, many of these enzyme-encoding genes are also expressed in the unopened pitcher; but in comparison to the open pitcher, the number of genes expressed is reduced. For instance, nepenthesin I and II are expressed in both the unopened and open pitchers whereas class IV chitinase is specifically expressed in the open pitcher. We also detected transcripts of microbial origin i.e. bacteria and fungi in all the five different parts/zones of the $N$. khasiana leaf; but in the digestive zone, these transcripts shared homology mostly to those of fungi. We also observed altered expressions of class III HOMEODOMAINLEUCINE ZIPPER (HD-ZIPIII) and ARGONAUTE (AGO) genes, thereby suggesting that genes specifying leaf polarity may play a key role in the development of the Nepenthes pitcher. Our findings suggest that N. khasiana pitchers employ a wide range of enzymes for prey digestion and plant defense, many of which are expressed prior to the opening of the lid, harbor mostly fungi in the digestive zone and probably evolved through altered expression of leaf polarity genes. 


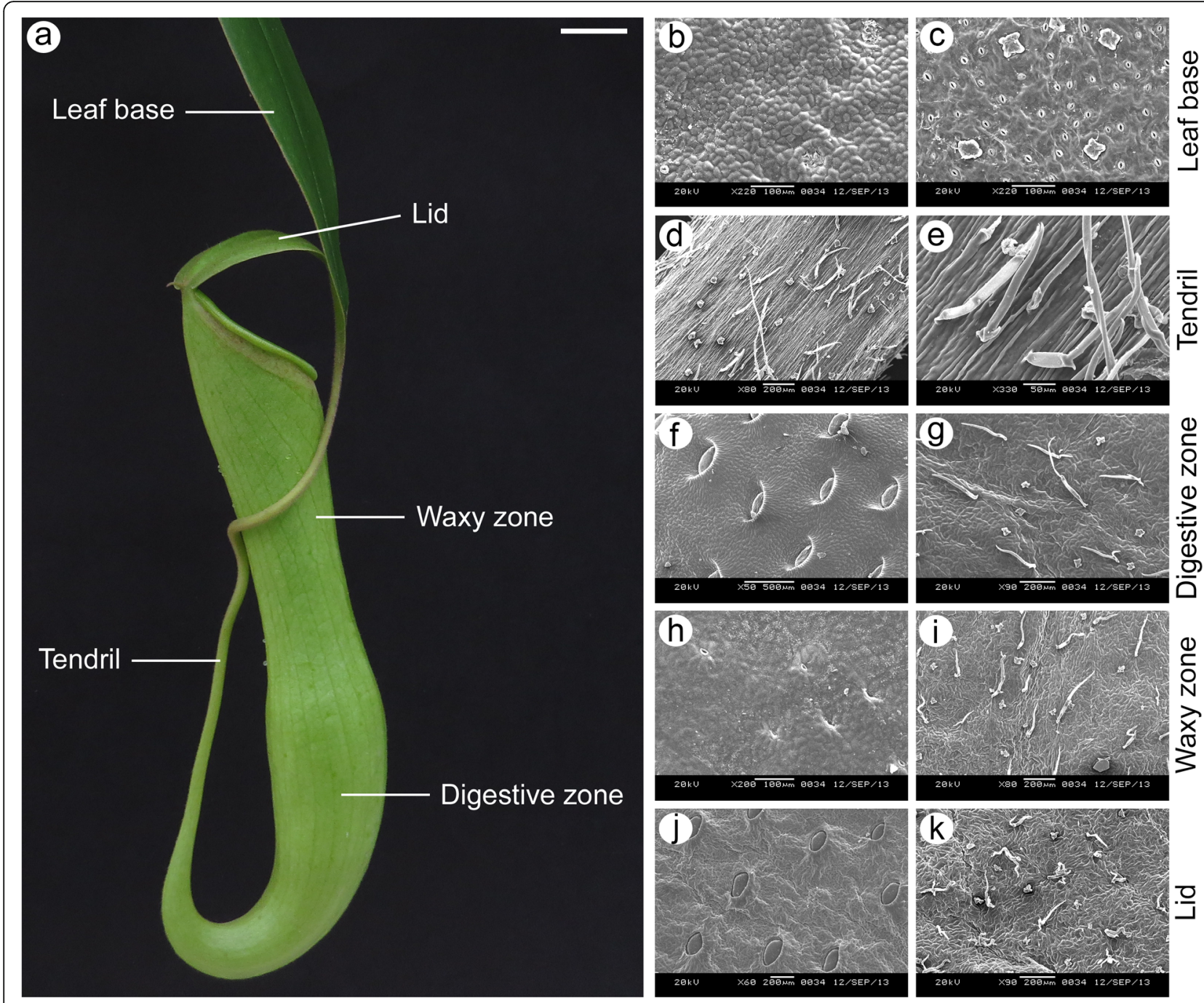

Fig. 1 Nepenthes khasiana leaf. a, the five distinct parts/zones of the N. khasiana leaf comprising the leaf base, tendril, digestive zone, waxy zone and lid $(\mathrm{bar}=1 \mathrm{~cm})$. $\mathbf{b}-\mathbf{k}$, SEM photomicrographs of the leaf base $(\mathbf{b}, \mathbf{c})$, tendril $(\mathbf{d}, \mathbf{e})$, digestive zone $(\mathbf{f}$, $\mathbf{g})$, waxy zone $(\mathbf{h}, \mathbf{i})$ and lid $(\mathbf{j}, \mathbf{k})$. Barring tendril, SEM images on the left represent the adaxial surfaces while the ones on the right depict the abaxial surfaces. $\mathbf{e}$ is a close-up of the tendril shown in (d)

\section{Results}

\section{Sequencing, de novo assembly and annotation}

RNA sequencing of the five different parts/zones of the $N$. khasiana leaf resulted in a total of 262 million highquality paired-end Illumina reads (Additional file 1: Table S1). Reads were combined into a single data set and assembled using the freely available software Trinity $[18,19]$ by applying the default settings to generate a reference de novo assembled transcriptome of the $N$. khasiana leaf. Redundant transcripts were removed from the Trinity generated assembly using cd_hit_est. The reference transcriptome contains 412,224 transcripts with a mean contig length and a maximum contig length of $0.695 \mathrm{~kb}$ and $23.743 \mathrm{~kb}$, respectively. The N50 value is $1.356 \mathrm{~kb}$. Figure S1 in Additional file 1 shows the length distribution of all assembled transcripts. Using BLASTX program [20], we then compared the assembled transcripts of length $\geq 200 \mathrm{bp}$ with the NCBI non-redundant protein database and retained matches with E-value cutoff $\leq 10^{-5}$ and similarity score $\geq 40 \%$. We found 99,604 assembled transcripts possessed at least one significant hit against the NCBI non-redundant protein database. At least $1 \mathrm{e}^{-5}$ confidence level was observed for around $60 \%$ of the transcripts, indicating high protein conservation (Additional file 1: Fig. S2a). About 79\% of the transcripts possessed protein level similarity of more than 60\% (Additional file 1: Fig. S2b). The predicted proteins from BLASTX were annotated against UniProt database. Out of 99,604 transcripts, 50,222 transcripts matched proteins available in the UniProt database. The organisms' names corresponding to the top BLASTX hit of each transcript was extracted and plotted in Additional 
file 1: Fig. S3. Beta vulgaris subsp. vulgaris emerges as the top organism with 9292 matching transcripts. 'Carbohydrate degradation' (249), 'amino-acid biosynthesis' (199) and 'protein modification' (126) were among the most abundant metabolic pathways mapped (Additional file 1: Fig. S4). Figure S5 in Additional file 1 shows the top $10 \mathrm{GO}$ terms identified in each category. Under the biological process category, 'DNA integration' is placed at the top while 'integral component of membrane' emerged as the top GO term under cellular component category. The molecular function category is represented at the top by 'nucleic acid binding'. We have submitted the RNA-seq data from the two biological replicates generated in this study to NCBI Short Read Archive and it can be accessed under accession number SRP064181.

\section{Transcript abundance estimation and differentially expressed genes}

We estimated transcript abundance along the $N$. khasiana leaf by mapping individual reads from each part/ zone to the reference transcriptome (length $\geq 200 \mathrm{bp}$ ) using Bowtie 2 [21]. About 95\% of reads, on average, were properly aligned to the reference transcriptome. The alignment summary is provided in Additional file 1: Table S2. We then extracted unique and shared transcripts in and among all the different tissue parts/zones. We detected highest number of uniquely expressed transcripts in the waxy zone (7373), followed by leaf base (1111), tendril (1001), digestive zone (898) and lid (346) (Fig. 2a). In the waxy zone, 24 GO molecular function terms are enriched, of which 15 are over-represented and 9 are under-represented. 'Protein dimerization activity' and 'oxidoreductase activity' emerged at the top for under- and over-represented molecular functions, respectively (Additional file 1: Fig. S6). Two GO molecular function terms showed enrichment in the leaf base, of which 'oxidoreductase activity' is over-represented and 'binding' is under-represented. In the tendril, 'RNA-directed DNA polymerase activity' and 'cysteine-type peptidase activity' make up for the two over-represented $\mathrm{GO}$ molecular function terms. Four GO molecular function terms were enriched in the digestive zone, while no enrichment was detected for the lid (Additional file 1: Fig. S6). Surprisingly, the uniquely expressed genes contributing to the top molecular function term ('structural constituent of cuticle') in the digestive zone showed homology to insect cuticle proteins. All five parts/zones of the $N$. khasiana leaf shared a common set of 27,208 expressed transcripts (Fig. 2a). From the correlation analysis of the five different samples, the waxy zone and lid as well as the digestive zone showed high correlation among each other (Fig. 2b). At the same time, these distinct parts/zones of the pitcher tube displayed a relatively higher correlation with the leaf base than the tendril. This implies that the leaf base and the pitcher share similar transcripts expressions patterns.

We then used the DeSeq software [22] to generate the read counts and fragments per kilobase of transcript per million mapped reads (FPKM) values. Figure S7 in Additional file 1 shows a distribution of the FPKM values. On the basis of the applied criteria [ $p$-value $<0.05]$, we identified 12,610 significantly DEGs along the $N$. khasiana leaf. Upon adjusting the $p$-value, the number of significantly DEGs reduces to 2386. The automated annotation software Mercator [23] was then used to generate a mapping file of the DEGs for overrepresentation and functional category enrichment analyses. The Mercator result shows that $56 \%$ of the data were assigned functions while no functions were assigned to the remaining $44 \%$ of the data (Additional file 1: Fig. S8). Overrepresentation analysis using Pageman [24] indicated that most enriched functions are specific to certain parts/zones of the $N$. khasiana leaf viz. minor $\mathrm{CHO}$ metabolism, cell wall, lipid metabolism, amino acid metabolism, S-assimilation, secondary metabolism, hormone metabolism, stress, misc. and transport (Fig. 3). Among the up-regulated genes, protein synthesis represents one of the enriched molecular functions overrepresented in the digestive zone of $N$. khasiana pitcher. It was earlier shown in the carnivorous plant Dionaea muscipula that de novo protein synthesis occurs simultaneously with the secretion of the digestive fluid, and part of the newly synthesized protein is also directly secreted into the fluid [25]. In light of this finding, our results suggest that de novo protein synthesis is also taking place in the pitcher of $N$. khasiana. Some genes were not assigned any functions and may represent those that are specific to $N$. khasiana (Fig. 3).

\section{K-means clustering and functional category enrichment analysis}

The significantly DEGs were then grouped according to the k-means clustering algorithm. Prior to k-means clustering, the number of clusters $\mathrm{k}$ was estimated using the Figures of Merit (FOM) application embedded in the $\mathrm{MeV}$ program [26]. The results show that the adjusted FOM decreases sharply and begins to level out after reaching 4 clusters (Additional file 1: Fig. S9). In addition to FOM, employing the gap statistic algorithm in $\mathrm{R}$ program resulted in 6 clusters (Additional file 1: Fig. S10). Therefore, the k-means clustering analysis was performed three times with each run generating 6 clusters using the K-means / K-medians Support Module (KMS) of the MeV program and applying the Kendall tau rank correlation. The final output consists of 18 consensus clusters in which all the member genes clustered together in at least $80 \%$ of the K-Means runs (Fig. 4a). 


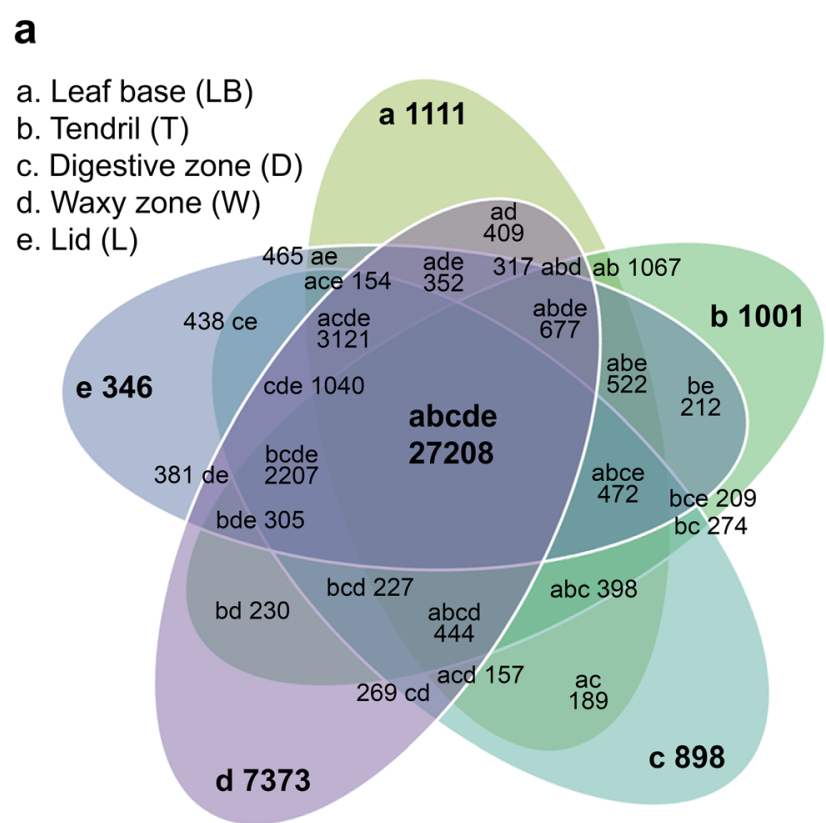

\section{b}

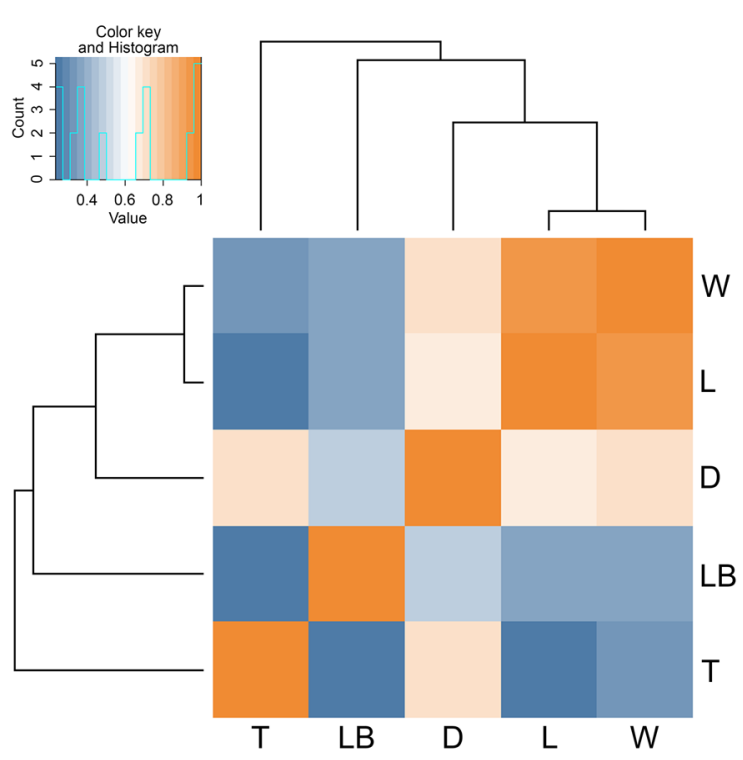

Fig. 2 Estimation of transcript abundance and correlation-based hierarchical clustering analysis. a, Unique and shared transcripts in/among the five different parts/zones of the $N$. khasiana leaf. Numbers represent expressed transcripts. $\mathbf{b}$, correlation-based hierarchical clustering of the five different samples based on the $\log _{2}$ FPKM values of 27,208 commonly expressed genes (red, positive correlation; blue, negative correlation). LB: leaf base; T: tendril; D: Digestive zone; W: waxy zone; L: lid

Cluster 1-6, 8, 11, 12, 14, and 15 consisted of genes that showed relatively higher expression in the digestive zone whereas genes of cluster 9 are expressed at higher levels in the waxy zone. Cluster 10 and 17 are represented by genes that are highly expressed in the lid and tendril, respectively. Cluster 18 comprises of genes that are expressed at higher levels in the leaf base. Genes of cluster 13 are expressed at higher levels in both the digestive and the waxy zones whereas genes of cluster 7 and 16 showed high expression in both the waxy zone and lid.

To test for the enrichment of Mapman functional categories in each cluster, a Wilcoxon statistic followed by the Benjamini-Hochberg correction was performed. Seven out of the 18 clusters showed various enriched functions (Fig. 4b). But most of the functional categories are enriched in cluster 12 . These include secondary metabolism, misc., and protein synthesis. The DEGs grouped in cluster 2 showed enrichment for secondary metabolism and protein synthesis. Protein synthesis is also enriched in cluster 4 whereas genes of cluster 5 showed enrichment for functions that are not assigned. Cluster 7 showed enrichment for development and unassigned functions. S-assimilation and amino acid metabolism are enriched in cluster 8 and 10, respectively. It was reported earlier that the concentration of aromatic amino acids increases during petal development in snapdragon, probably to attract potential pollinators [27]. Therefore, aromatic amino acid metabolism in the lid of the $N$. khasiana pitcher may be associated with the attraction of insect prey. The 'not assigned' function is also enriched in cluster 5, 8 and 12, and may contain genes that are specific to N. khasiana (Fig. 4b).

\section{Transcriptome profiling identifies genes involved in prey digestion and plant defense}

Table 1 shows a list of transcripts sharing homology to enzyme-encoding genes known to play a role in prey digestion and plant defense. A complete list of all the enzymes detected in the different parts/zones of the $N$. khasiana leaf along with their descriptions, functions, transcript IDs and abundances can be found in Additional file 2: Table S4. Among them, aspartic proteinases nepenthesin I and nepenthesin II (DN32357. c0_g1_i1, DN96960_c0_g1_i1), class IV chitinase (DN167792_c0_g1_i1, DN43389_c0_g2_i1, DN43389_ c0_g2_i2), C-terminal peptidase (DN61492_c2_g2_i1, DN61492_c2_g2_i2), defensin (DN3077_c0_g2_i1), GDSL esterase/lipase (DN43304_c0_g1_i1, DN43304 c0_g2_i1), peroxidase (DN42192_c0_g1_i1, DN42192_ c0_g1_i2), phosphatase (DN6769_c0_g2_i1), and serine carboxypeptidase (DN40795_c0_g2_i1, DN40795_c0_g2 i2) showed high levels of expression in the digestive zone with low or lack of expressions in the other parts/zones of the N. khasiana leaf (Table 1). Transcripts encoding type III polyketide synthase also showed high expression in the digestive zone. In addition, some transcripts 


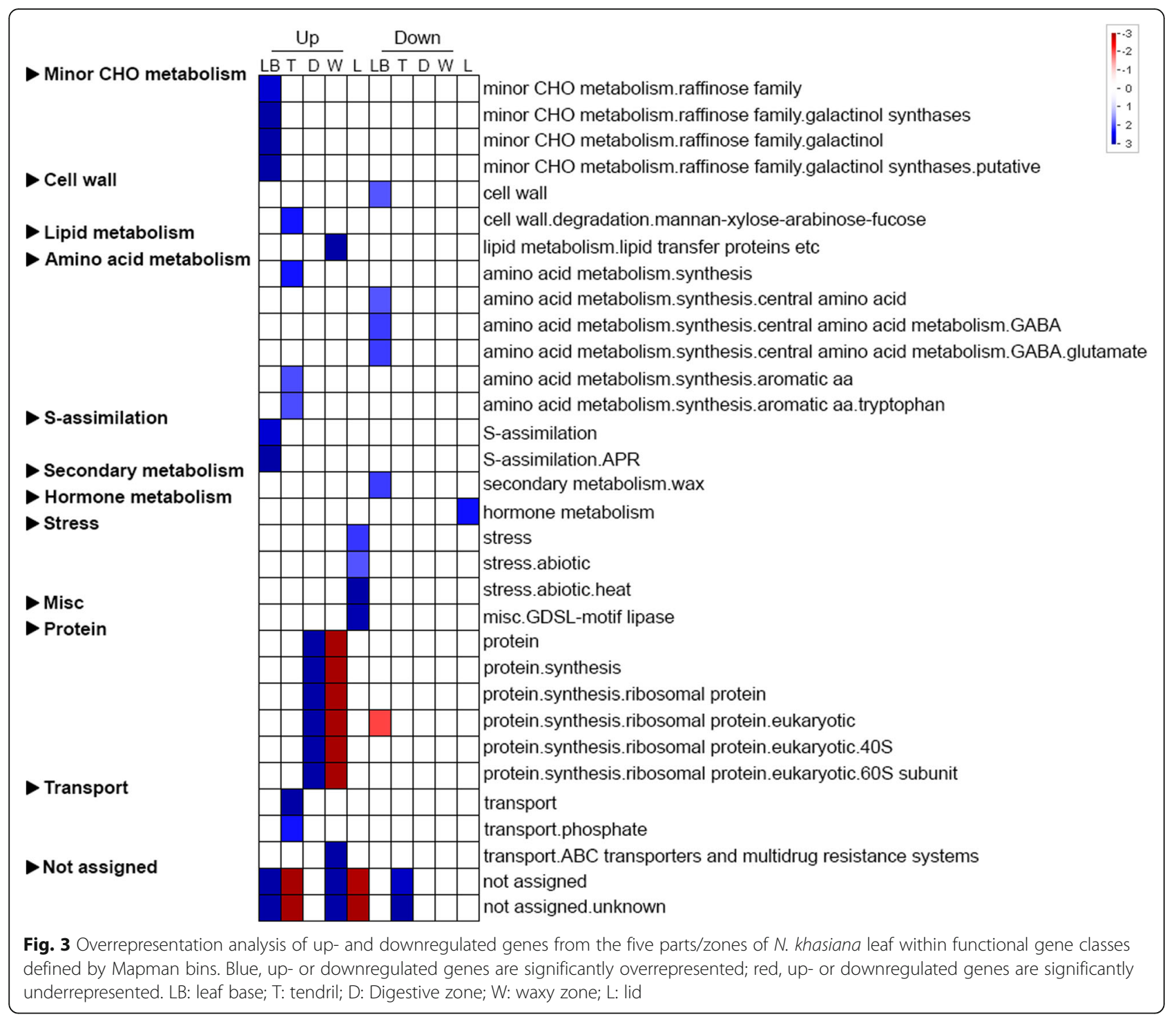

encoding enzymes such as acid phosphatase (DN46307 c0_g2_i1, DN46369_c0_g1_i1 and DN46369_c0_g1_i4), acidic endochitinase (DN61615_c0_g1_i1 and DN61615_ c0_g1_i2), C-terminal peptidase (DN61492_c2_g1_i9, DN61492_c2_g1_i2), glucanase (DN60686_c0_g1_i1), serine carboxypeptidase (DN55176_c1_g1_i1), S-like RNase (DN31936_c0_g1_i1, DN31936_c0_g1_i2) and thaumatin-like proteins (DN58459_c0_g2_i6, DN60173_c0_g2_i12, DN60173_c0_g2_i2) are expressed throughout the $N$. khasiana leaf with elevated levels in the digestive zone. A single transcript (DN14283_c0_g1_i1) which encodes a lipid transfer protein is also expressed throughout the $N$. khasiana leaf with increased expression in the pitcher tube. Validation of the RNA-seq data using real time qPCR analysis indicated a strong correlation between the two data (Fig. 5).
Genes known to play a role in prey digestion and plant defense are also expressed in un-opened pitchers of $N$. khasiana

A question arises as to whether similar kinds of digestive enzyme-encoding genes are also expressed in unopened $N$. khasiana pitchers, in which the lid is still attached to the pitcher tube (Additional file 1: Fig. S11). To address this question, we examined the transcriptome profile of an unopened pitcher generated independently of this study [28]. The results show that most transcripts sharing homology to key enzymes involved in prey digestion and plant defense are also expressed in unopened $N$. khasiana pitchers (Additional file 3: Table S5). Commonly expressed between the opened and unopened pitchers include genes that encode acid phosphatase, nepenthesin I and II, GDSL esterase/lipase, peroxidase, type III polyketide synthase, 


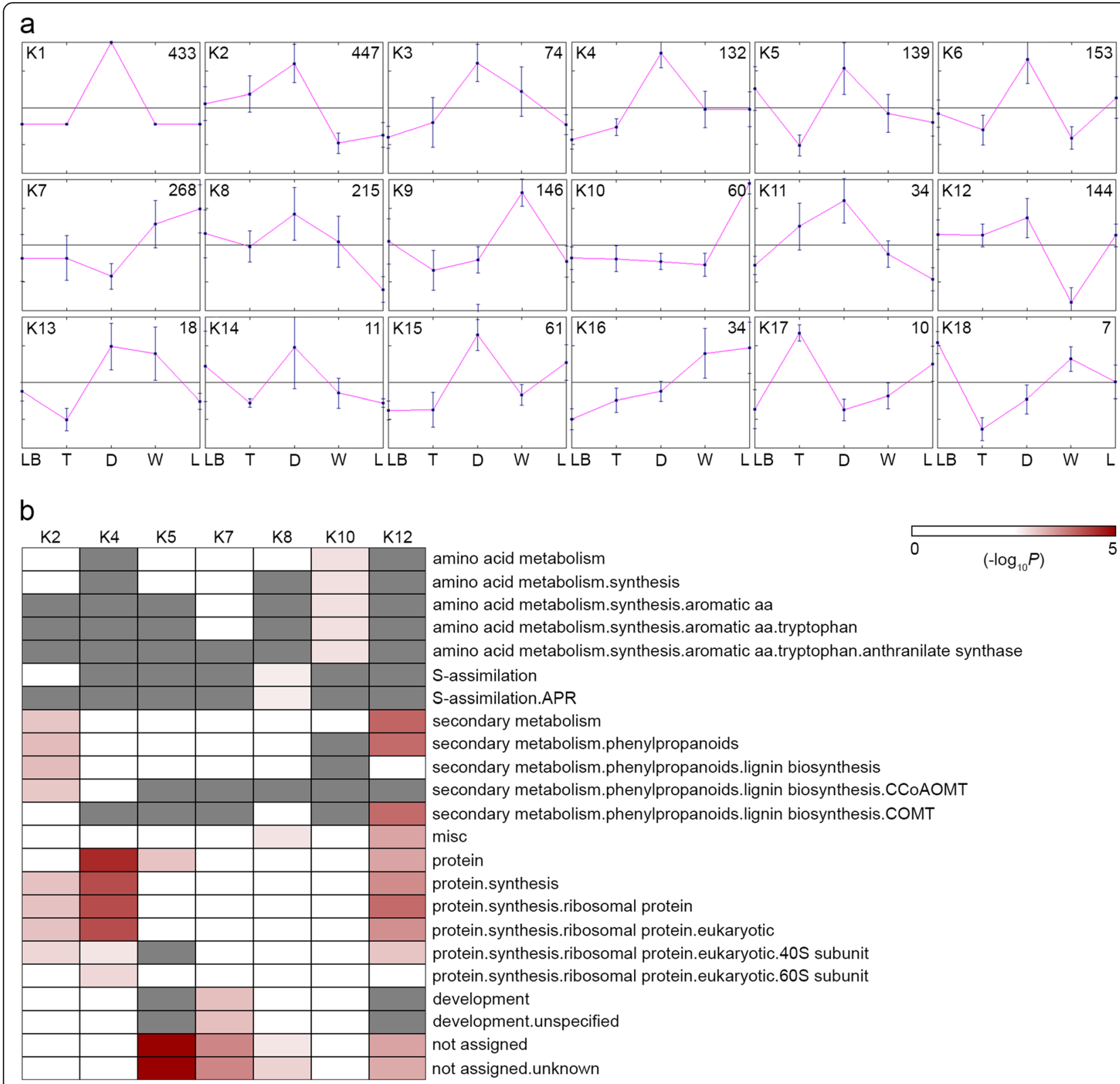

Fig. 4 Clustering and functional category enrichment analyses of 2386 DEGs. a, 18 k-means clusters were identified along the five different parts/ zones of the N. khasiana leaf, with each cluster showing different expression patterns (numbers denote the number of DEGs in each cluster; error bars denote mean $\pm \mathrm{SE}$ ). $\mathbf{b}$, functional category enrichment (MapMan bins) among the 7 major clusters (No enrichment for remaining 11 clusters). Red, significant enrichment; white, non-significant; gray, not-detected

pathogenesis-related protein and several others whereas genes that encode for class IV chitinase, Cterminal peptidase, defensin, $S$-like ribonuclease, thaumatin-like protein and $\alpha$-xylosidase are specifically expressed in the opened pitchers (Fig. 6). Thus, the presence of captured insects or pathogenic microbes, as a result of the opening of the lid, triggers the expression of more number of genes encoding other key digestive enzymes.

\section{Transcriptome data suggests the presence of microbial transcripts}

Our RNA-seq results indicated the presence of transcripts showing homology to genes of microbial origin i.e. bacteria and fungi (Additional file 4: Table S6 and Additional file 5: Table S7). Transcripts of bacterial origin were mostly detected in the waxy zone, although a few were also identified in the digestive zone (Additional file 1: Fig. S12). In terms of the number of transcripts 


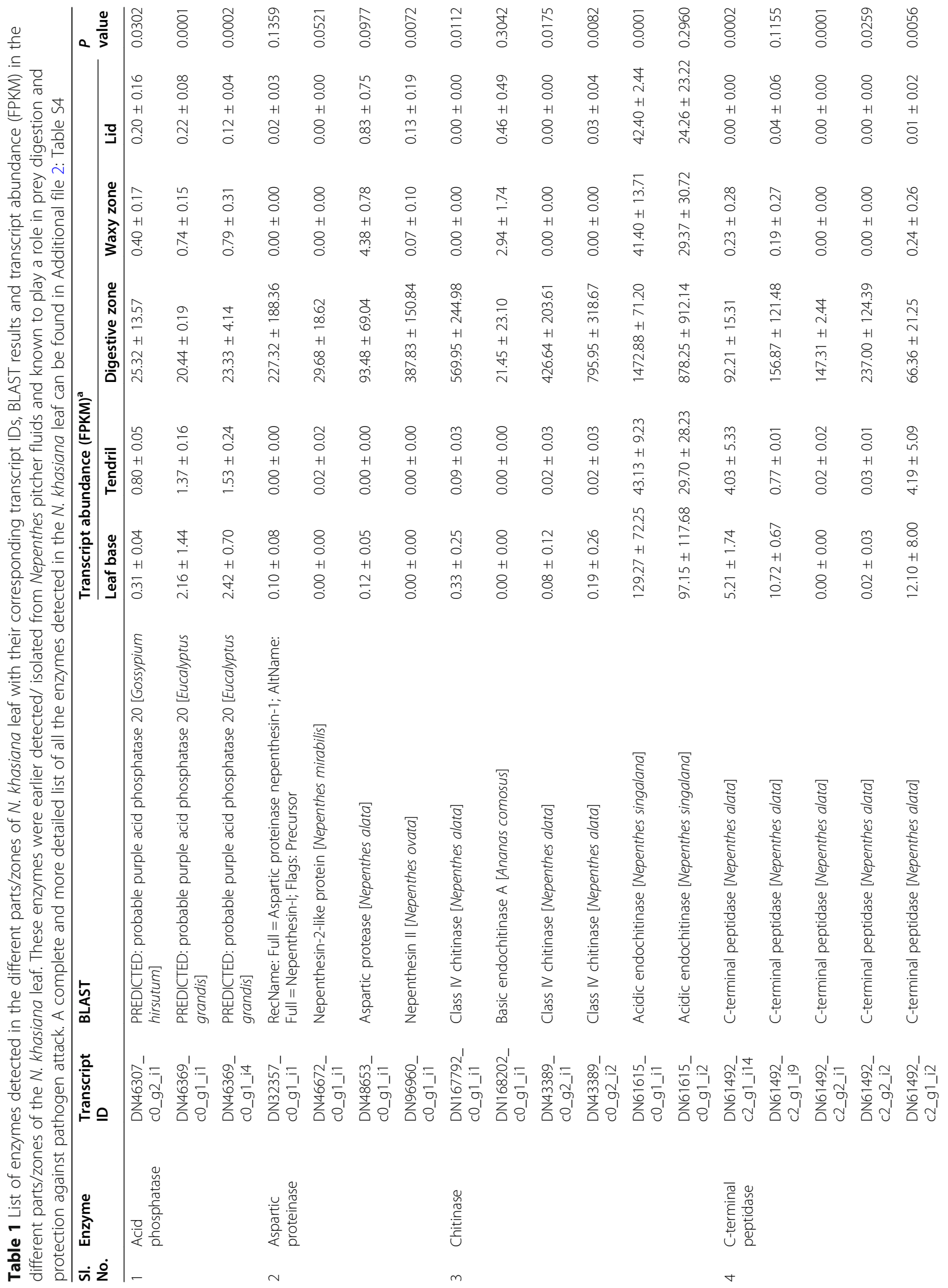




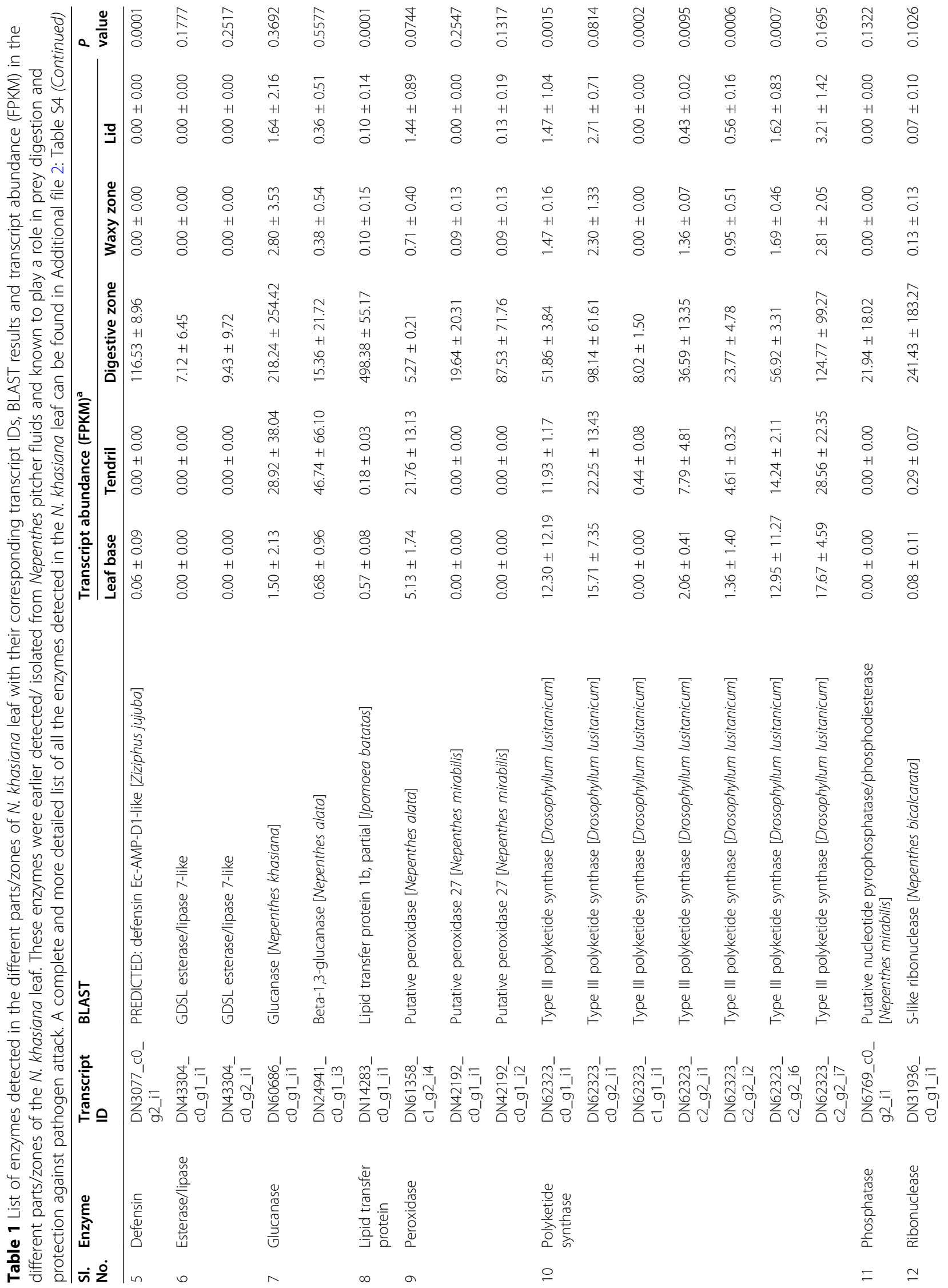




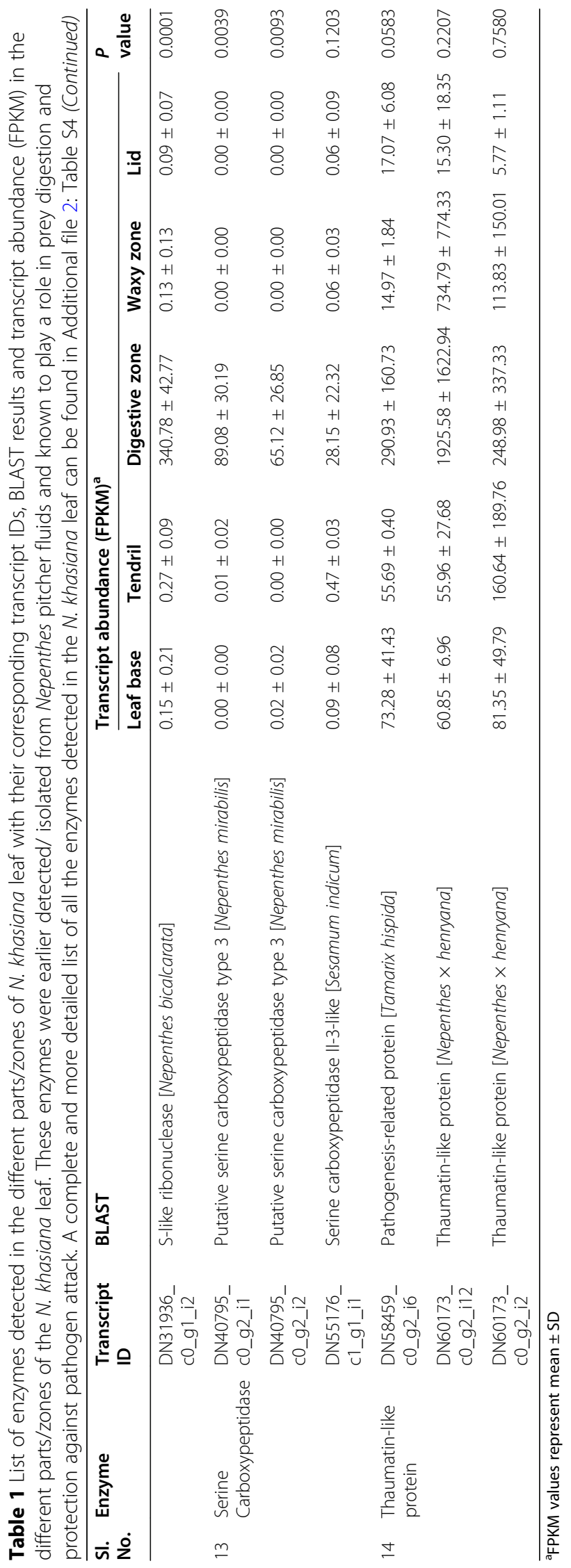




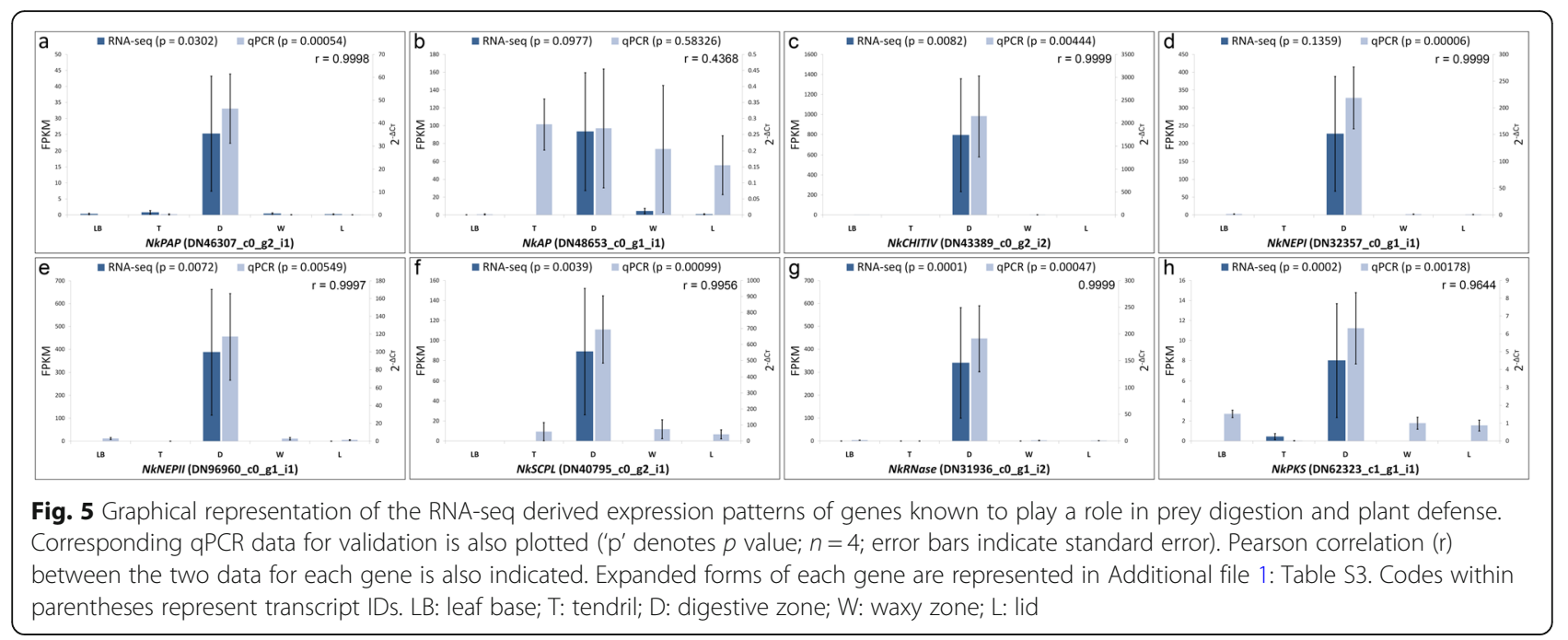

detected, the most abundant bacteria include Chryseobacterium (50), Microbacterium (34), Micrococcus (26), Staphylococcus (12), and Streptococcus (10). Although a number of transcripts that correspond to enzymes having proteolytic and nucleolytic activities viz. restriction endonuclease (DN49567_c0_g1_i1), LD-carboxypeptidase (DN53339_c0_g1_i2), M23 family peptidase (DN18977_c0_g1_i1), excinuclease ABC subunit B (DN55294_c1_g1_i1), and HNH endonuclease (DN19920_c0_g3_i1) were identified, these were detected on the waxy zone rather than the digestive zone.
We also detected transcripts of fungal origin, most of which are confined to the different parts/zones of the pitcher tube while some occur throughout the highly specialized $N$. khasiana leaf (Additional file 5: Table S7). Our data further suggest that fungi predominantly occur in the digestive zone as compared to bacteria (Additional file 1: Fig. S12). In cases where fungal transcripts were detected in the digestive zone, some correspond to genes encoding enzymes involved in protein degradation and hydrolysis of organic phosphates. These include acid phosphatase (DN225864_c0_g1_i1), acid protease (DN47168_c0_g1_i1, DN47168_c0_g2_i1), and peptidase

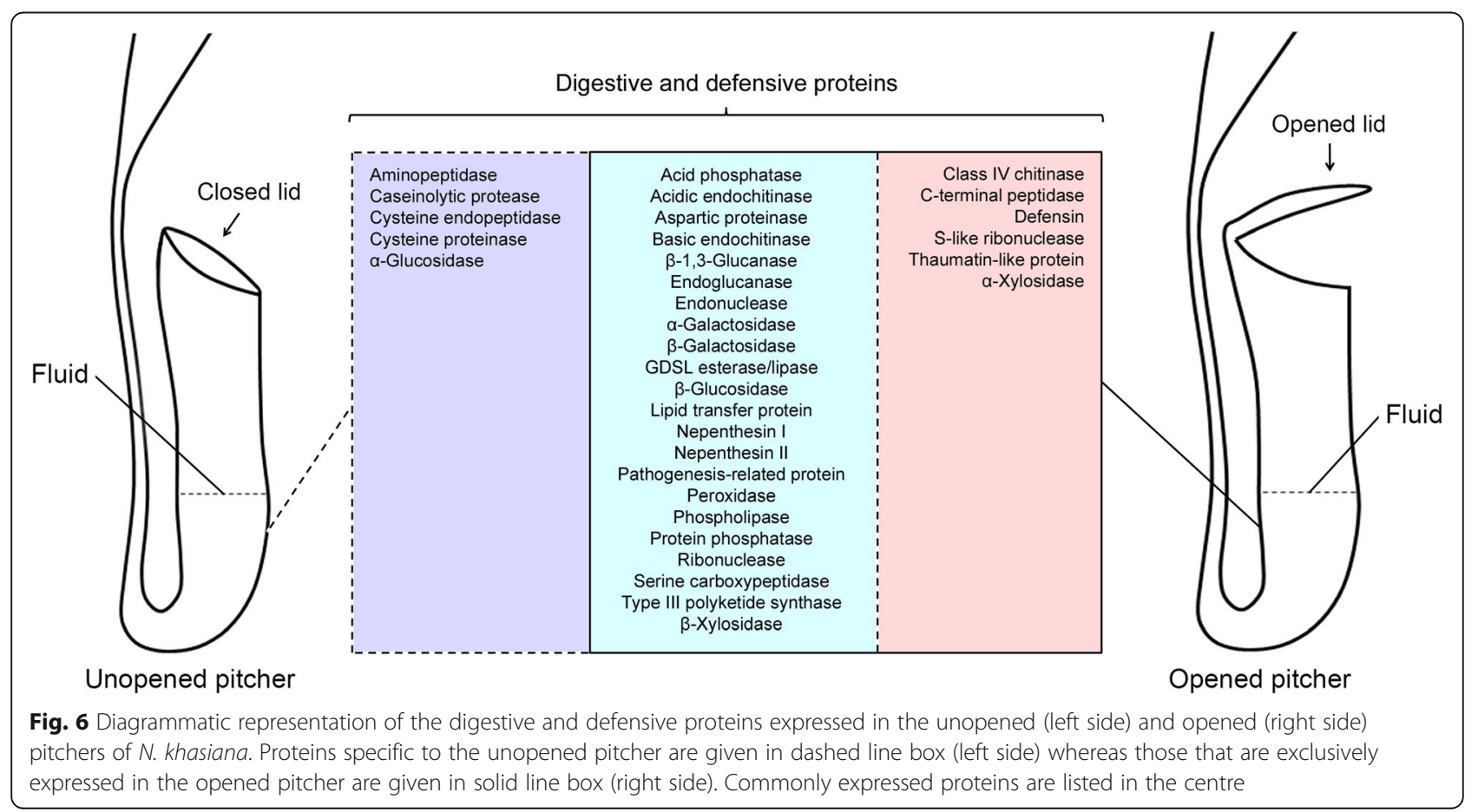


C1B (DN94491_c0_g1_i1), all of which belonged to Metschnikowia bicuspidata, a fungal parasite. Interestingly, we identified beetle-borne fungi which include Grosmannia clavigera, Lodderomyces elongisporus, Ophiostoma piceae and Spathaspora passalidarum. Besides, an acidophilic filamentous fungus Acidomyces richmondensis and an ant-associated fungus Phialophora attae were also identified. Based on their transcript numbers, most dominant fungi include Candida (141), Clavispora lusitaniae (60), Grosmannia clavigera (12), Kwoniella (18), Metschnikowia (167), Mycosphaerella eumusae (11), Ophiostoma piceae (15) and Sporothrix (64).

Transcripts of microbial origin were also detected in the unopened pitchers of N. khasiana (Additional file 6: Table S8 and Additional file 7: Table S9). Although the number of bacteria and fungi detected is relatively small, both opened and unopened pitchers do share common transcripts of microbial origin. These transcripts belong to the fungal genera Aspergillus and Talaromyces and the bacterial genera Aeromonas, Burkholderia, Pantoea and Pseudomonas.

\section{Ultrastructure and anatomy of the highly specialized $N$. khasiana leaf}

SEM photomicrographs showed that the arrangement of stomata in the abaxial surface of the leaf base of $N$. khasiana does not follow the one-cell spacing rule as seen in the model plant Arabidopsis thaliana [29]. But the leaf base possesses more number of stomata as compared to the abaxial surfaces of the different parts/zones of the pitcher tube (Fig. 7a-e). On the other hand, the tendril completely lacks stomata (Fig. 7b). These observations find additional support from nail polish epidermal imprints, in which the leaf base recorded a stomatal index of $11.19 \pm 0.96 \%$ while the digestive zone, waxy zone and lid recorded $0.97 \pm 0.31 \%, 1.26 \pm 0.33 \%$, and
$1.36 \pm 0.42 \%$ stomatal indexes, respectively (Additional file 1: Fig. S13). Cross sections along the $N$. khasiana leaf showed that the adaxial/abaxial polarity is maintained in the leaf base but becomes indistinct in the different parts/zones comprising the pitcher tube (Fig. $7 f-j$ ).

\section{Expression patterns of key regulatory genes involved in stomatal development and leaf polarity specification} Taking cues from histology and SEM photomicrographs of the five distinct parts/zones of the $N$. khasiana leaf, we examined the expression pattern of genes involved in stomatal development and leaf polarity specification. Since the investigated samples represent mature tissues, we sought to determine the expression pattern of genes acting at the late stage of stomatal development. Based on the information available for the model plant Arabidopsis (see Additional file 1: Note S1) and assuming that similar genes control stomata formation in N. khasiana, we predicted that $N k Y D A$ and its downstream signaling components (NkMKK4/NkMKK5 and NkMPK3/ NKMPK6) would be downregulated in the leaf base and relatively lesser in the pitcher but upregulated in the tendril of N. khasiana. We also determined the expression of NKSCRM, anticipating an increased expression in the tendril considering the fact that loss-of-function scrm Arabidopsis mutants displayed increased stomatal densities [30]. Our results show that almost all genes behaved as predicted (Fig. 8a-d). In N. khasiana, the adaxial/abaxial polarity in the leaf base is maintained but in the different parts/zones comprising the pitcher tube, polarity is lost (Fig. 7f-j; also see Pavlovič et al. [4]). Because of this loss in polarity specification, we sought to determine the expression pattern of leaf polarity genes along the highly specialized $N$. khasiana leaf. Members of the class III HOMEODOMAIN-LEUCINE ZIPPER (HDZIPIII) gene family such as PHABULOSA (PHB),

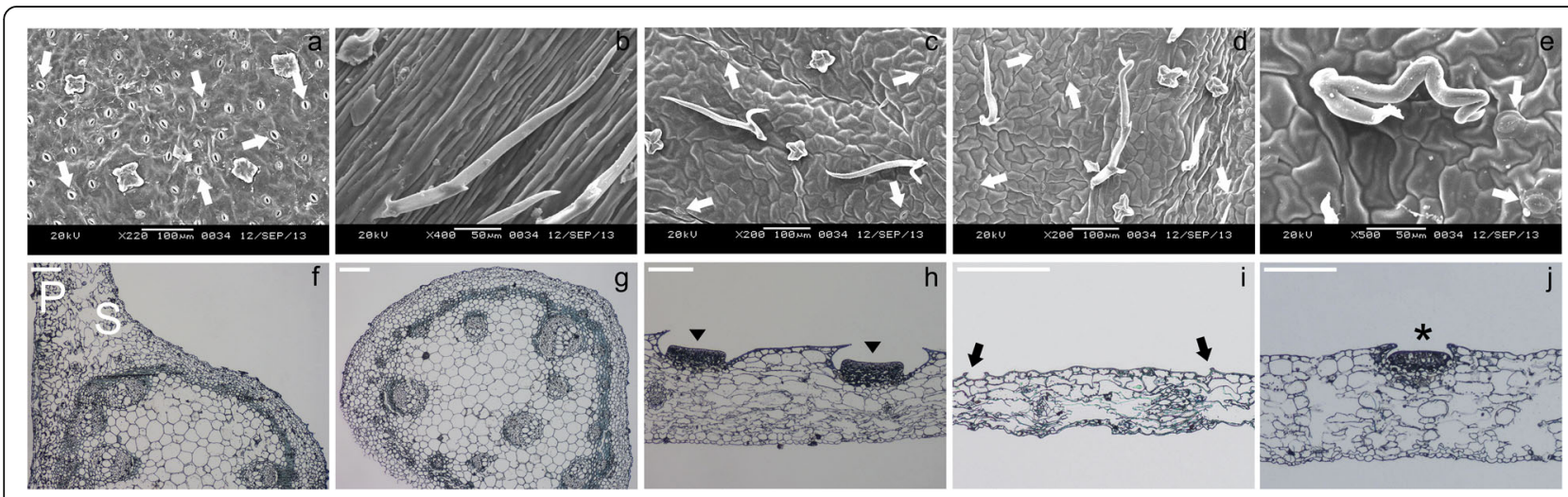

Fig. 7 Stomatal density and distribution as well as leaf polarity in N. khasiana leaf. a-e, SEM photomicrographs of the abaxial surfaces of the different parts/zones of the $N$. khasiana leaf (stomata are indicated by white arrow). $\mathbf{f}-\mathbf{j}$, light micrographs cross sections of the five different parts/ zones of the $N$. khasiana leaf (P: palisade parenchyma; S: spongy parenchyma; arrow head denotes digestive glands; black arrow shows the lunate cells; nectary gland is indicated by an asterisk). a, $\mathbf{f}$ - leaf base; $\mathbf{b}, \mathbf{g}$ - tendril; $\mathbf{c}, \mathbf{h}$ - digestive zone; $\mathbf{d}, \mathbf{i}$ - waxy zone; $\mathbf{e}, \mathbf{j}$ - lid. $\mathbf{f}-\mathbf{j}$, bar = 50 m 


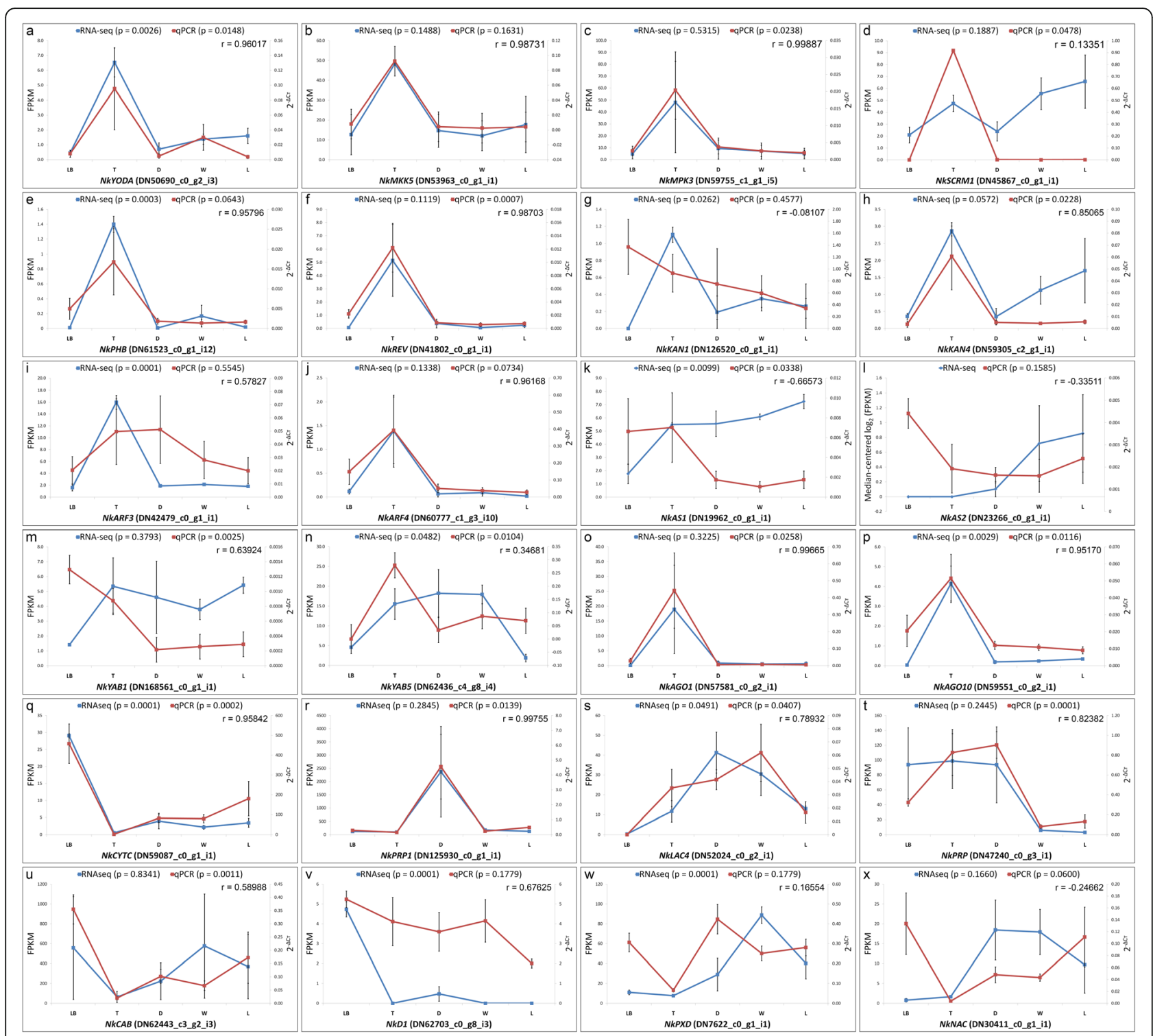

Fig. 8 Graphical representation of the RNA-seq derived expression patterns of genes known to play a role in stomatal density and distribution (ad) and leaf polarity specification (e-p) (blue line; refer Note S1 in Additional file 1). Corresponding qPCR data for validation is also plotted (red line; ' $p$ ' denotes $p$ value; $n=4$; error bars indicate standard error). $\mathbf{q}-\mathbf{x}$ represent both RNA-seq and qPCR data of randomly selected genes for validation. Pearson correlation ( $r$ ) between the two data for each gene is also indicated. LB: leaf base; T: tendril; D: Digestive zone; W: waxy zone; L: lid. The expanded form of each gene is represented in Additional file 1: Table S3

PHAVOLUTA (PHV) and REVOLUTA (REV), the KANA $D I(K A N)$ gene family encoding nuclear-localized GARPdomain transcription factors, the AUXIN RESPONSE FACTOR (ARF) gene family, the carboxy-terminal PAZ and PIWI domain containing ARGONAUTE (AGO) genes and the MYB domain ASYMMETRIC LEAVES (AS) 1 and LOB domain AS2 transcription factors specify adaxial/abaxial leaf polarity in Arabidopsis. We found that the expression of transcripts homologous to Arabidopsis class III HD-ZIP (NkPHB \& NkREV) and ARGONAUTE (NkAGO1 \& NkAGO1O) genes were upregulated in the tendril (Fig. 8e, f, o, p). qPCR further validates the
RNA-seq results (Fig. 8e, f, o, p). Figures 8q-x represent qPCR-based validation of additional RNA-seq data of randomly selected genes.

\section{Discussion}

Pitchers of $N$. khasiana employ a wide range of enzymes for prey digestion

Our analysis of the transcriptome data shows that $N$. khasiana pitchers employ a wide range of enzymes for prey digestion (Table 1). Among them, chitinase is the only enzyme that has previously been isolated and characterized in N. khasiana [16]. Using degenerate PCR, 
Eilenberg et al. [16] identified four class I chitinase genes in N. khasiana (NkChit1b-1 and 2, NkChit2b-1 and 2). They found that both chitinases are expressed in the pitcher (tissue) in response to the addition of chitin into closed $N$. khasiana pitcher traps to mimic captured prey. However, NkChit2b expression is also detected prior to chitin induction implying that this enzyme may represent a constitutively expressed housekeeping chitinase. Our results corroborated their findings whereby two (DN61615_c0_g1_i1, DN61615_c0_g1_i2) out of six detected transcripts sharing homology to acidic endochitinases showed expression throughout the different parts/ zones of the $N$. khasiana leaf. The expression of one transcript (DN168202_c0_g1_i1) is restricted to the pitcher tube while the remaining three transcripts (DN167792_c0_g1_i1, DN43389_c0_g2_i1, DN43389_ c0_g2_i2), which corresponds to class IV chitinase, are expressed at high levels in the digestive zone. The latter transcripts match the one identified by Hatano \& Hamada in $N$. alata, and their protein products are most likely secreted into the pitcher fluid of $N$. khasiana to aid prey digestion and protection against pathogen attack.

Our results further indicated that transcripts (DN32357_c0_g1_i1, DN96960_c0_g1_i1) with sequence homology to nepenthesin I and II are expressed at high levels in the digestive zone of $N$. khasiana. Nepenthesin belongs to a different class of acid proteinases with specificity to aspartic acid residues [31]. Their relationship (i.e. nepenthesin I and II) with other aspartic proteinases (APs) is unclear; hence are regarded as a novel subfamily of APs with the distinction of being secreted into the extracellular space (digestive fluid), unlike other orthologous APs [31]. Likewise, and based on the RNA-seq derived expression patterns, the putative nepenthesin I and II of $N$. khasiana are probably secreted into the digestive fluid to help in protein degradation. On the contrary, the expressions of four APs homologs isolated from $N$. alata are not limited to the digestive zones but were also detected in tissues of the root, stem, leaf, and tendril with the highest levels being recorded in leaf tissues [32]. Athauda et al. [31] argued that these may represent vacuolar APs, different from nepenthesin. This is also evident in our study, wherein the expression of a single transcript (DN48653_c0_g1_i1) was recorded in other zones/parts of the N. khasiana leaf, therefore implying that both extracellular and intracellular APs are expressed in the $N$. khasiana leaf.

Additional transcripts (DN31936_c0_g1_i1, DN31936_ c0_g1_i2) showing relatively higher expressions in the digestive zone corresponds to the S-like ribonuclease of $N$. bicalcarata. Matthews [33] was the first to report the presence of ribonuclease in the pitcher fluids of several Nepenthes species based on experiments that indicated degradation of TMV RNA. Similarly, Stephenson and Hogan [34] reported the presence of ribonuclease activity in pitcher fluid of $N$. ventricosa, and identified a putative RNase clone having 66\% identity to S-like RNase. This was further corroborated by a recent study that suggested the probable role of S-like RNases in plant carnivory because of their high expression in the trapping organs of carnivorous plants [35]. In noncarnivorous plants, S-like RNases are induced upon phosphate starvation or mechanical injury [36], probably to promote phosphate mobilization in the event of nutrient limitation. In $N$. khasiana, high expression of the S-like RNase in the digestive zone would have facilitated phosphate mobilization for growth and development. The availability of phosphate in the pitcher fluid is made possible by the action of phosphatases on preyderived phosphate containing compounds. Phosphatase activity has been detected in the digestive glands of $N$. tobaica and these enzymes are most likely secreted into the pitcher fluid to aid phosphate hydrolysis [37]. Our data showed expression of transcripts sharing homology to acid and protein phosphatases, some of which (DN46307_c0_g2_i1, DN46369_c0_g1_i1, DN46369_c0_ g1_i4, DN6769_c0_g2_i1) are highly expressed in the digestive zone, providing additional support to Płachno et al. [37] observations on $N$. tobaica.

The present data also showed the presence of transcripts sharing homology to putative peroxidases. Peroxidases have been identified in a number of Nepenthes species and are known to play an important role in plant protection against pathogens [38]. They may also aid in protein degradation via the production of reactive oxygen species [39]. One transcript (DN61358_c1_g2_i4) from our data showed homology to peroxidases isolated from $N$. alata [38]. However, its expression level is low as compared to other putative peroxidases identified in our results (DN42192_c0_g1_i1, DN42192_c0_g1_i2). These putative peroxidases are expressed throughout the $N$. khasiana leaf with higher expression in the digestive zone. This relatively large number of highly expressed putative peroxidases demonstrates the crucial role that peroxidases play in prey digestion and protection against pathogen attack.

Our transcriptome data also points to the presence of transcripts encoding $\mathrm{C}$-terminal peptidases, five of which are expressed at higher levels in the digestive zone (Table 1). C-terminal peptidase represents a class of serine proteases, identified earlier in the digestive fluid of $N$. alata [40]. Interestingly, our analysis of the transcriptome data also indicated the presence of a single transcript (DN3077_c0_g2_i1) showing homology to the cysteine-rich protein defensin. These proteins act mostly against fungi [41]. 
In a recent study, Rottloff et al. [42] identified 20 new proteins that are possibly secreted into the pitcher fluid of five different Nepenthes species. These include serine carboxypeptidases, $\alpha$ - and $\beta$-galactosidases, lipid transfer proteins and esterases/lipases. We also show here the presence of transcripts sharing homology to these putative proteins, thereby confirming Rottloff et al. [42] observations. Among them, two transcripts (DN40795_ c0_g2_i1, DN40795_c0_g2_i2) encoding serine carboxypeptidase match those identified by Rottloff et al. [42], both of which are expressed exclusively in the digestive zone. Taken together, our findings suggest that N. khasiana plants express a broad array of enzymes-encoding genes helpful in the digestion of captured prey, some of which may be representatives of the genus Nepenthes.

\section{Pathogenesis-related (PR) genes are expressed in $\mathbf{N}$. khasiana pitchers to inhibit the growth of pathogenic microbes}

Once captured prey gets digested, the pitcher fluid becomes a rich source of essential nutrients supporting the growth and development of the plant. In turn, it also favors the growth of bacteria and fungi. Thus, there exists a competition between the Nepenthes plant and microbes for the available nutrients in the pitcher fluid [15]. To make full use of the dissolved nutrients, Nepenthes plants have adopted a strategy of inhibiting the growth of potential microbial competitors or pathogens through the release of pathogenesis-related (PR) proteins. It was shown earlier that PR proteins such as thaumatin-like proteins and $\beta$-1,3-glucanases are secreted into the pitcher fluid of $N$. alata [30]. Our results show the presence of transcripts sharing homology to thaumatin-like proteins and glucanases. Two transcripts (DN60173_c0_g2_i12, DN60173_c0_g2_i2) of the thaumatin-like proteins match those identified earlier in Nepenthes, all of which are highly expressed in the digestive zone. Although the expression of a single transcript (DN60686_c0_g1_i1) showing homology to glucanase is expressed at higher levels in the digestive zone, the expressions of two $\beta-1,3$-glucanase transcripts (DN24941_c0_g1_i3, DN62573_c0_g1_i5) from N. khasiana that matches the one isolated from $N$. alata is relatively low, implying that $\beta$-1,3-glucanases are not strongly induced in $N$. khasiana. This may also be the case in $N$. alata, as silver-stained SDS-PAGE gel of Hatano and Hamada [30] points to weak signal thereby corroborating our results. Lipases have also been detected in the pitcher fluids of several Nepenthes species $[38,39,42,43]$; but their role as yet is not clear, although it has been suggested that they promote protein availability through cell membrane disruptions [44]. We detected several transcripts that match GDSL-like lipase, some of which are expressed exclusively in the digestive zone (DN43304_c0_g1_i1, DN43304_c0_g2_i1). GDSL LIPASE-LIKE 1 (GLIP1) has been shown to induce systemic resistance against pathogens in Arabidopsis [45]. Because of its increased expression in the digestive zone, the result points to its role in plant immunity. In addition, we identified a number of transcripts showing homology to genes encoding type III polyketide synthase (PKS) of a carnivorous plant Drosophyllum lusitanicum. Type III PKSs are involved in the biosynthesis of secondary metabolites [46], one of which includes naphthoquinones [47]. The exclusive expression of type III PKS genes in the digestive zone of $N$. khasiana suggests that naphthoquinones are required for defense against microbial pathogens. Besides these enzymes, class IV chitinase is another PR protein that aid in plant defense and our results show that it is highly expressed in the pitcher. Based on our results, thaumatin-like proteins, class IV chitinase and GDSL-like lipase provide protection to $N$. khasiana against pathogen attack.

\section{Transcripts of fungal origin are mostly detected in the digestive zone}

The probable role of microbes in prey digestion was brought into limelight following the isolation of bacteria from the fluid of unopened $N$. alata pitchers [48]. This continued to be reported $[13,14]$, although several other pieces of evidence point to a microbe-free digestive fluid from unopened Nepenthes pitchers [12, 15]. We do not attempt to resolve this controversy in the present paper; however, we do feel that a discussion on this aspect is warranted because of the detection of transcripts of microbial origin. Our results show the presence of both bacteria and fungi in the different parts/zones of the $N$. khasiana leaf. This is expected as the tissues were sampled from opened N. khasiana pitchers and reports are available that indicated presence of microbe either as endophytes or coming from the phyllosphere [14, 48]. But what's interesting is the pattern in which these microbes are detected: transcripts of bacterial origin occur mostly in the waxy zone while fungal transcripts are present all along the leaf, the majority of which are detected in the digestive zone. This is in line with the findings of Buch et al. [15], which showed that bacteria die when incubated in the pitcher fluid whereas fungi survived but failed to grow. It also points to the important role fungi plays if at all microbes are involved in prey digestion or competition against available nutrients. Fungal endophytes have been isolated from several Sarracenia and Nepenthes species $[49,50]$ and among them, Aspergillus, Colletotrichum, Meyerozyma, Penicillium and Trichoderma represent some of the genera detected in the present study. Meyerozyma guilliermondii is phosphatesolubilizing yeast which promotes nutrient uptake in maize and lettuce and provides protection against fungal 
pathogens [51]. This evidence points to the existence of a symbiotic relationship between $N$. khasiana and fungi. We do not rule out the role of bacteria in prey digestion as certain bacterial transcripts were detected in the digestive zones. As is the case in the human gut, these might actually help in the digestion of captured prey. In fact, we detected transcripts matching bacteria reported in the human gut, e.g. Bifidobacterium [52]. Surprisingly, only two bacterial species identified in the present study match those that are identified recently from the digestive fluid of a Nepenthes species using 16S rDNA and MALDI-TOF MS [53]. These include Leifsonia aquatica and Myroides odoratimimus. Although Chan et al. [53] did not specify the species name, these results imply that different Nepenthes species harbor different microbial communities. This proposition also finds support from the study of Takeuchi et al. [14], which detected only one bacterial operational taxonomic unit (OTU) common among all the 16 Nepenthes samples investigated. In 14 samples, however, Takeuchi et al. [14] detected 22 shared OTUs, some of which were also detected in the present study. These include Acinetobacter, Bacillus, Micrococcus, Pedobacter, Pseudomonas, and Rhodococcus.

\section{Unopened pitchers of $N$. khasiana express several genes involved in prey digestion and protection against pathogen attack}

Several reports have pointed to the presence of enzymatic activities in the fluid of unopened Nepenthes pitchers. Tökés et al. [44] identified two proteases of different molecular weights and demonstrated the presence of lipase activity in $N$. macferlanei. Several enzymes were also observed in the unopened pitchers of three Nepenthes species viz. $N$. alata, $N$. tobaica, and $N$. ventricosa [54]; and in certain species of Nepenthes, both unopened and opened pitchers show the same levels of phosphatase activity [55]. Prior to the opening of the pitcher lid, it is likely then that most Nepenthes pitchers express several genes involved in prey digestion and protection against pathogen attack. This notion finds support from our analysis of the transcriptome data generated from an unopened N. khasiana pitcher. The results indicated that most transcripts sharing homology to key enzymes involved in prey digestion and plant defense are also expressed in the unopened pitcher. For example, nepenthesin I and II are commonly expressed in both opened and unopened pitchers. On the other hand, class IV chitinase is specifically expressed in the opened pitcher (Fig. 6). Our findings suggest that in response to the presence of captured prey or pathogenic microbes, $N$. khasiana plants employ a broader spectrum of digestive enzymes.
Leaf polarity genes may play a key role in the development of the Nepenthes pitcher

Our correlation-based hierarchical clustering analysis of the commonly expressed genes indicated similar expression patterns between the leaf base and the different parts/zones of the pitcher tube. These similarities not only suggest functional relationship but also points to similar cellular processes [56] underlying the development of these two distinct structures i.e. leaf base and the pitcher. Figure 7 shows that the Nepenthes pitcher possesses stomata, albeit at reduced number in comparison to the photosynthetically efficient leaf base. This suggests recruitment of the underlying genetic mechanism that governed stomatal development processes. However, their low density as evidenced by SEM micrographs and epidermal imprints indicate reduced expression of genes that positively regulates stomatal development. Assuming that genes known to play a role in the development of stomata in the model plant Arabidopsis thaliana are also responsible for such developmental events in $N$. khasiana, we could essentially make predictions of their expression patterns along the $N$. khasiana leaf. Most genes behaved as predicted (Fig. 8), and in cases where they follow the predicted pattern, these are also well-correlated by the qPCR results (Fig. $8 \mathrm{a}-\mathrm{c})$. Interestingly, cross sections along the $N$. khasiana leaf depicted leaf base as a typical angiosperm leaf with maintained polarity showing distinct adaxial and abaxial domains (Fig. 7f). However, cells of the pitcher, as well as the lid, are not differentiated into palisade and spongy parenchyma (Fig. 7h-j; also refer Pavlovič et al. [4]), indicating a loss of polarity specification. We recently show that the pitcher of a young $N$. khasiana leaf share anatomical features with the young in-rolled leaf base lamina [28], suggesting that the loss of polarity in the pitcher occurs at later stages of pitcher development. The loss of adaxial-abaxial polarity in the Nepenthes pitcher may be associated with reduced KAN1 expression and/or increased expression of AS2 as evidenced in Arabidopsis, whereby leaf anatomy of loss-of-function kan1 mutants and AS2 overexpressed plants displayed disrupted adaxial-abaxial polarity as compared to wildtype $[57,58]$. We extended our investigation into genes involved in leaf polarity specification and determined their expression pattern along the $N$. khasiana leaf. However, the RNA-seq derived expression pattern of NkKAN1 and NkAS2 genes do not follow the predicted pattern (Fig. 8g, l); rather, expression of the class III HOMEODOMAIN-LEUCINE ZIPPER (HD-ZIPIII) and ARGONAUTE (AGO) genes were upregulated in the tendril (Fig. 8e, f, o, p). Previous reports have shown that the constitutive expression of the adaxial HD-ZIPIII genes $P H B$ and $R E V$ transformed the flat ovate-shaped leaf of Arabidopsis into rod- or trumpet-shaped leaves 
[59-61]. These leaves show an abundance of trichomes on the epidermal surfaces, characteristics of an adaxialized leaf phenotype [62]. Besides showing increased $P H B / R E V$ expression, the tendril of $N$. khasiana is made up of relatively higher number of trichomes (Figs. 1 and 7b), in line with those observed in the leaves of the Arabidopsis phb1-d mutant [62]. Trichomes were also observed on the abaxial surfaces of the $N$. khasiana pitcher comprising the digestive zone, waxy zone and lid (Fig. 7c-e).

\section{Conclusions}

In the present study, we analyzed and report the transcriptome data of the highly specialized $N$. khasiana leaf comprising the leaf base lamina, tendril and the different parts/zones of the pitcher tube viz. digestive zone, waxy zone and lid. We found that irrespective of whether the pitcher lid is opened or closed, many of the enzymeencoding genes involved in prey digestion and plant defense are commonly expressed. This observation suggests that Nepenthes plants equip themselves with the necessary machinery required for prey attraction, capture and digestion prior to the opening of the pitcher lid. In addition, our findings imply that fungi may play a crucial role over bacteria in the digestion of captured prey if at all microbes are involved, and may exist as symbionts of the Nepenthes plants. Furthermore, we show that the adaxial/abaxial polarity is maintained in the leaf base but become disrupted in the different parts/zones comprising the pitcher tube. Our examination of the RNA-seq derived expression patterns of a number of genes known to play a role in leaf polarity specification suggest that class III HD-ZIP genes may play a key role in the development of the Nepenthes pitcher.

\section{Methods}

\section{Plant material and tissue harvesting}

Nepenthes khasiana plants used in the present study are found in the wild located at Jaraiñ, Jaiñtia Hills District, Meghalaya ( $\left.25^{\circ} 18.651^{\prime \prime} \mathrm{N}, 92^{\circ} 07.786^{\prime \prime} \mathrm{E}\right)$. Tissues representing the five different parts/zones of the $N$. khasiana leaf viz. leaf base, tendril, digestive zone, waxy zone and lid were harvested at two separate dates, one in the month of June 2013 and another in October 2013 (Additional file 1: Fig. S14). We felt that collecting samples at two different dates will not affect the results as these samples represent vegetative tissues of the same kind; rather, this sampling strategy would add more strength to our findings. Mature leaves were selected having developed pitchers characterized by an opened lid and the presence of captured, killed insects in the digestive fluid. The fluid was drained off prior to tissue freezing. Tissue samples were then frozen in liquid nitrogen, transferred into dry ice, transported to Jawaharlal Nehru University, New Delhi and kept at $-80^{\circ} \mathrm{C}$, until further processing. Tissue samples were collected by Jeremy Dkhar on two separate trips. Identification of the plant species was made by Jeremy Dkhar based on reliable sources available in the literature. A voucher specimen having a deposition number 17466 has been deposited in the Herbarium section of CSIR-Institute of Himalayan Bioresource Technology, Palampur, India.

\section{Histological and scanning electron microscopy (SEM) analyses}

Small tissue pieces of each part/zone of the N. khasiana leaf were fixed in $0.1 \mathrm{M}$ phosphate buffer containing $2.5 \%$ glutaraldehyde (pH 7.2). Fixed tissue samples were dehydrated through a graded ethanol series, embedded in saturated paraffin wax, cross-sectioned, de-waxed in xylene, stained with $0.05 \%$ toluidine blue and viewed and photographed using a Nikon Eclipse Ti-S Inverted Microscope available at Central Instrumentation Facility, School of Life Sciences, JNU, New Delhi. For SEM, samples were processed at Sophisticated Analytical Instrumentation Facility, North-Eastern Hill University, Shillong. Fixed samples were washed in buffer overnight, post fixed in $1 \%$ osmium tetraoxide, dehydrated through increasing concentrations of acetone, dried using an HCP-2 (Hitachi) critical point-drier, coated with gold and viewed under JEOL JSM-6360 SEM.

\section{RNA extraction, library preparation and sequencing}

We extracted total RNA from all five distinct parts/ zones of the $N$. khasiana leaf using Raflex Kit (Bangalore Genei, India) and/or Spectrum Plant Total RNA Kit (Sigma, USA) as per the instructions of the manufacturers. Quality check of the extracted RNA samples was performed using the Agilent 2100 Bioanalyzer. Extracted RNAs showed three distinct bands (28S, $18 \mathrm{~S}$ and $5 \mathrm{~S}$ ) on EtBr-stained formaldehyde agarose gel (Additional file 1: Fig. S15). RNA integrity number (RIN) values of the extracted RNAs ranged from 6.6-8.5. Library preparation and sequencing were performed at the Centre for Cellular and Molecular Platforms, Bangalore, India. One microgram of RNA each was used for library preparation and mRNA was purified using the polydT Oligo beads. The mRNA was then fragmented followed by cDNA synthesis. End repair, A-Tailing and adapter ligation were performed followed by PCR enrichment for $15 \mathrm{cy}$ cles. The Agilent Bioanalyzer was used to validate the generated libraries and sequencing was performed on an Illumina HiSeq 1000 platform as per the recommended protocol of the manufacturer, to generate $2 \times 100 \mathrm{bp}$ paired-end data. The five different parts/zones of the $N$. khasiana leaf were harvested from two separate 
individual plants and sequenced separately. Thus, two biological replicates were used for RNA-seq.

\section{Data pre-processing and de-contamination}

The data pre-processing and de-contamination steps were performed as mentioned in Dkhar and Pareek [28].

\section{De novo transcriptome assembly, annotation and differential expression analysis}

Transcriptome reads were pooled into a single data set and de novo assembled using Trinity [18, 19], applying the default settings. We then aligned individual reads from each tissue i.e. leaf base, tendril, digestive zone, waxy zone and lid to the assembled reference transcriptome to estimate gene expression using Bowtie2 version 2.2.2. We allowed up to 1-mismatches in the seed region (length $=31 \mathrm{bp}$ ) and all multiple mapped position were reported. The FPKM values were calculated using SciGenom Labs Pvt. Ltd. Perl script. The assembled transcripts were then annotated using a SciGenom Labs Pvt. Ltd. pipeline CANoPI (Contig Annotator Pipeline). Transcripts with FPKM $\geq 1$ and minimum length $\geq 200$ were selected for annotation against the NCBI nonredundant protein database using BLASTX 2.2.28 program [20] with E-value cut-off $\leq 10^{-5}$ and similarity score $\geq 40 \%$. BLASTX hits transcripts were also annotated against the UniProt database. Transcripts with read count $\geq 1$ were selected for differential gene expression analysis using DESeq 3.2.0 [22]. The analysis was carried out in pairwise combinations between parts/zones - for example leaf base vs. tendril, tendril vs. leaf base, leaf base vs. digestive zone, and so on - to identify upregulated and downregulated genes in each part/zone. Transcripts with adjusted $p$-value $($ FDR $) \leq 0.05$ and log fold change $(\log F C) \geq 1$ or $\leq-1$ were considered significantly differentially expressed.

\section{Correlation analysis}

We used the freely available R software (https://www.rproject.org/) to perform the correlation analysis among the five different parts/zones of the $N$. khasiana leaf as mentioned in Dkhar and Pareek [28].

\section{Overrepresentation analysis}

Prior to running overrepresentation analysis, a mapping file of the DEGs was generated using the automated annotation software Mercator [23]. Here, all DEGs sequences were used as input sequences and uploaded as a single file in fasta format into the Mercator web application available at http://www.plabipd.de/portal/web/ guest/mercator-sequence-annotation. Each input sequence is expected to map to one or more MapMan bins. A Fisher's exact test followed by the BenjaminiHochberg correction as implemented in PageMan software [24] was used to identify functional MapMan categories with significant differences among the different parts/zones of the $N$. khasiana leaf.

\section{K-means clustering and functional category enrichment analyses}

Prior to clustering, the number of clusters $k$ was estimated using the Figures of Merit (FOM) application embedded in the MeV program [26]. The FPKM values were added throughout by 1 and $\log _{2}$ transformed before running FOM. Five runs were performed and all runs showed similar results. In addition to FOM, the gap statistic algorithm [63] in R (https://www.r-project.org/) was also employed to estimate the number of clusters $k$. After estimating $\mathrm{k}(\mathrm{k}=4)$, we then performed $\mathrm{k}$-means clustering of the significantly DEGs ( $\log _{2}$ transformed FPKM) using the K-means / K-medians Support (KMS) module in $\mathrm{MeV}$ and applying the Kendall tau rank correlation. KMS was performed four times. Functional MapMan category enrichment analysis for each cluster was performed by applying the Wilcoxon statistics and Benjamini Hochberg multiple testing correction as implemented in Pageman [24].

\section{Identifying genes involved in prey digestion and plant defense}

We manually searched the list of annotated transcripts showing significant differential expressions to identify genes involved in prey digestion and protection against pathogen attack. We then checked their abundance and compared their expression patterns among the five different parts/zones of the $N$. khasiana leaf.

\section{Transcript profiling of key regulatory genes involved in plant development}

Similarly, we examined the expression levels of key regulatory genes involved in stomatal development and leaf polarity specification. We extended our investigation into the total list of annotated transcripts to identify genes of interest and compared their expression patterns among the five different parts/zones of the $N$. khasiana leaf.

\section{Validation of RNA-seq data using real-time qPCR}

The RNA-seq results were validated using real-time qPCR. cDNAs of four biological replicates were synthesized using the First Strand cDNA synthesis kit (Thermo Scientific). Transcripts for validation were selected from a list of identified genes known to play a role in prey digestion and plant defense, stomatal development and leaf polarity. In addition, eight randomly selected genes were also used for validation. We initially tested four endogenous genes Actin, Elongation factor (ELF), Glyceraldehyde-3-phosphate dehydrogenase (GAPC2) 
and Ubiquitin $(U B Q)$ \} for stable expression, out of which one $(E L F)$ was used for the normalization of the expression of the selected genes. Real-time qPCR assays were carried out as mentioned in Dkhar and Pareek [28]. Three technical replicates were analyzed for each sample and data analysis was performed using 7500 Software v 2.0.5 (Applied Biosystems). The $2^{-\Delta \mathrm{CT}}$ values were generated and these were then compared with the RNA-seq derived FKPM values. ANOVA of SPSS was performed to test the significance level $(p<0.05)$ and Pearson correlation ( $r$ ) was calculated to check for correlation between the RNA-seq and qPCR data. Table S3 in Additional file 1 contains the list of qPCR primers.

\section{Identifying genes involved in prey digestion and plant defense in the unopened pitchers of $N$. khasiana}

Unopened pitchers of Nepenthes are known to contain digestive fluid, though the amount is lesser when compared to the fluid of opened Nepenthes pitchers [64]. It may also contain protein at very low levels, which increases upon opening of the pitcher lid, or at levels identical to those of an opened pitcher [55]. In such a scenario, it is expected then that the unopened pitchers of Nepenthes should show the expression of genes involved in prey digestion and plant defense. To confirm, we examined the list of significantly DEGs of an unopened $N$. khasiana pitcher to identify genes involved in prey digestion and protection against pathogen attack. We then compared them with those genes identified from the opened pitchers of $N$. khasiana. The transcriptome data of the unopened $N$. khasiana pitcher was generated independently and with a different objective from the present study [28] and can be accessed online at NCBI under accession numbers SRR4340048 (raw reads) and GFDV00000000 (assembled transcript sequences). All bioinformatic analysis steps leading to the identification of DEGs in the unopened $N$. khasiana pitcher were performed as mentioned above.

\section{Supplementary information}

Supplementary information accompanies this paper at https://doi.org/10. 1186/s12870-020-02663-2.

Additional file 1: Fig. S1. Length distribution of the assembled transcripts of $N$. khasiana leaf. Fig. S2. a, E-value distribution of BLASTX hits of $N$. khasiana leaf transcriptome against the NCBI non-redundant protein database. b. BLASTX similarity score distribution of N. khasiana leaf transcriptome with the NCBI non-redundant protein database. Fig. S3. Top 50 organisms distribution of the assembled transcriptome using BLASTX. Fig. S4. Metabolic pathway mapping of the assembled transcriptome. Fig. S5. Top $10 \mathrm{GO}$ terms in biological processes, cellular components and molecular functions. Fig. S6. Over-represented and underrepresented molecular functions in each of the five different parts/zones of the N. khasiana leaf. No enrichment was detected in the lid. Fig. $\mathbf{S 7 .}$ Transcript expression distribution in the five tissue samples. Fig. $\mathbf{S 8 .}$ Assigning Mapman 'bins' to the DEGs using the automated annotation software Mercator available online at https://mapman.gabipd.org/app/ mercator. Fig. S9. Determining the number of clusters for k-means clustering using the Figures of Merit (FOM) application embedded in the MeV program. The adjusted FOM decreases sharply and levels out after reaching 4 clusters. Fig. S10. Determination of the number of clusters for k-means clustering using the gap statistic algorithm in R. The number of clusters is 6 . Fig. S11. N. khasiana plant showing several developing leaves, each attaining distinct stages of development. Stage 5 represents the leaf ( $L 5)$ showing pitcher expansion with the lid remaining unopened. Transcriptome data of stage 5 was included in the present study. White vertical/horizontal lines specify the dissected regions of each stage. Bar $=$ $6 \mathrm{~cm}$. Fig. S12. Relative abundance of bacterial transcripts against fungal transcripts across the different parts/zones of the N. khasiana leaf. LB: leaf base; T: tendril; D: digestive zone; W: waxy zone; L: lid. Fig. S13. Epidermal nail polish imprints of the abaxial surfaces of four different parts/ zones of the $\mathrm{N}$. khasiana leaf. These imprints are then used to estimate stomatal density [1]. Arrow head denotes stomata. Fig. S14. Sample collection for transcriptome sequencing of $\mathrm{N}$. khasiana leaf. a, Nepenthes khasiana plants growing in the natural habitat at Jaraiñ, Jaiñtia Hills District, Meghalaya. b, mature pitcher with fully opened-lid and prominent wings formed along the sides of the pitcher. $\mathbf{c}-\mathbf{d}$, preparation of the different parts/zones of the leaf viz. leaf base, tendril, digestive zone, waxy zone and lid for preservation in liquid nitrogen. Note: transition regions represent those regions in the leaf that indicate a shift from one part/ zone to another. Fig. S15. Extraction and quality check of total RNA from $N$. khasiana leaf. a, total RNA extracted from five different parts/zones of the N. khasiana leaf. The full-length gels photos are provided in Fig. S16. below; $\mathbf{b}$, total RNA profile and the corresponding peaks resulting from a quality check of the isolated total RNA (leaf base) using an Agilent Bioanalyzer; c, electropherogram profile of RNA library. Fig. S16. Full-length gels photos of the total RNAs isolated from the five different parts/zones of the $N$. khasiana leaf. The gel photo on the left shows the extracted RNAs of the digestive zone, tendril and the leaf base (lanes 4, 5 and 6). Since the RNA of the tendril is of poor quality (lane 5), isolation was repeated to yield a better one (lane 8 of middle gel photo). The gel photo on the right shows the extracted RNAs of the lid and the waxy zone (lanes 4 and 5). The RNA gel images of each part/zone were cropped and presented in Fig. S15a. Note S1. Stomatal density and distribution in the model plant Arabidopsis thaliana. Table S1. RNA sequencing read statistics of the different tissue parts of two N. khasiana leaf samples. We performed MD5 CheckSum on the FASTQ files under each category (raw and quality filter passed reads) to ensure data integrity. Table S2. Alignment summary of the individual reads to the reference transcriptome. Table S3. List of qPCR primers used for the validation of RNA-seq derived transcript expression pattern.

Additional file 2: Table S4. List of transcripts encoding enzymes involved in prey digestion and plant defense in N. Khasiana.

Additional file 3: Table S5. List of transcripts encoding enzymes involved in prey digestion and plant defense detected in the unopened pitchers of $N$. khasiana.

Additional file 4: Table S6. List of transcripts of bacterial origin.

Additional file 5: Table 57. List of transcripts of fungal origin.

Additional file 6: Table S8. List of transcripts of bacterial origin detected in the unopened pitchers of N. Khasiana.

Additional file 7: Table S9. List of transcripts of fungal origin detected in the unopened pitchers of $N$. khasiana.

\section{Abbreviations}

AGO: ARGONAUTE; DEGs: Differentially expressed genes;" FPKM: Fragments per kilobase of transcript per million mapped reads; HD-ZIPIII: Class III HOMEODOMAIN-LEUCINE ZIPPER; REV: REVOLUTA; SEM: Scanning electron microscopy

\section{Acknowledgements}

The authors acknowledge the Editor and two anonymous reviewers for critical reading and suggestions to improve the manuscript. The authors are grateful to the Centre for Cellular \& Molecular Platforms, Bangalore for help in sequencing the Nepenthes leaf transcriptome. The authors thank 
Scigenom Labs Pvt. Ltd., Kerala for help in data analysis (assembly, annotation and differential expression analysis).

\section{Authors' contributions}

JD and AP conceived the project. JD and AP designed the experimental workflow of the project. JD performed the experiments. YKB and AL helped with the data analysis. JD wrote the manuscript with crucial inputs from all co-authors. All authors approved the final draft of the manuscript.

\section{Funding}

This work was financially supported by grants from the Department of Science \& Technology (DST), Government of India (DST INSPIRE Faculty Scheme IFA12-LSPA-07). DST played no role in the study design, data collection and analysis, decision to publish, or preparation of the manuscript for publication.

\section{Availability of data and materials}

The datasets generated and analyzed during the current study are available in the NCBI Short Read Archive under accession number SRP064181.

\section{Ethics approval and consent to participate}

The use of plant parts in the present study complies with international, national and/or institutional guidelines. Permission to collect leaf samples of the endangered N. khasiana from Jaraiñ, Jaiñtia Hills District, Meghalaya was granted by the Chief Wildlife Warden, Forest \& Environment Department, State Government of Meghalaya, India vide Office Order No. 20 dated July 1, 2020.

\section{Consent for publication}

Not applicable.

\section{Competing interests}

The authors declare that they have no competing interests.

\section{Author details}

'Stress Physiology and Molecular Biology Laboratory, School of Life Sciences, Jawaharlal Nehru University, New Delhi 110067, India. ${ }^{2}$ Agrotechnology Division, CSIR-Institute of Himalayan Bioresource Technology, Palampur, Himachal Pradesh 176061, India. ${ }^{3}$ School of Computational and Integrative Sciences, Jawaharlal Nehru University, New Delhi 110067, India.

\section{Received: 21 July 2020 Accepted: 23 September 2020}

Published online: 17 November 2020

\section{References}

1. Albert VA, Williams SE, Chase MW. Carnivorous plants: phylogeny and structural evolution. Science. 1992;257:1491-5.

2. Ellison AM, Gotelli NJ. Energetics and the evolution of carnivorous plants_Darwin's 'most wonderful plants in the world'. J Exp Bot. 2009;60: 19-42.

3. Król E, Płachno BJ, Adamec L, Stolarz M, Dziubińska H, Trębacz K. Quite a few reasons for calling carnivores 'the most wonderful plants in the world'. Ann Bot. 2012;109:47-64.

4. Pavlovič A, Masarovičová E, Hudák J. Carnivorous syndrome in Asian pitcher plants of the genus Nepenthes. Ann Bot. 2007;100:527-36.

5. Juniper BE, Burras J. How pitcher plants trap insects. New Sci. 1962;13:75-77

6. Gaume L, Giusto BD. Adaptive significance and ontogenetic variability of the waxy zone in Nepenthes rafflesiana. Ann Bot. 2009;104:1281-1291.

7. Bauer U, Federle $W$. The insect-trapping rim of Nepenthes pitchers surface structure and function. Plant Signal Behav. 2009;4:1019-23.

8. Bauer U, Clemente CJ, Renner T, Federle W. Form follows function: morphological diversification and alternative trapping strategies in carnivorous Nepenthes pitcher plants. J Evol Biol. 2012;25:90-102.

9. Bauer U, Federle W, Seidel H, Grafe TU, loannou CC. How to catch more prey with less effective traps: explaining the evolution of temporarily inactive traps in carnivorous pitcher plants. Proc R Soc B. 2015;282: 20142675.

10. Gaume L, Forterre YA. Viscoelastic deadly fluid in carnivorous pitcher plants. PLoS One. 2007;2:e1185.
11. Bonhomme V, Pelloux-Prayer H, Jousselin E, Forterre Y, Labat JJ, Gaume L. Slippery or sticky? Functional diversity in the trapping strategy of Nepenthes carnivorous plants. New Phytol. 2011;191:545-54.

12. Biteau F, Nisse E, Miguel S, Hannewald P, Bazile V, Gaume L, et al. A simple SDS-PAGE protein pattern from pitcher secretions as a new tool to distinguish Nepenthes species (Nepenthaceae). Am J Bot. 2013;100:24782484

13. Chou LY, Clarke CM, Dykes GA. Bacterial communities associated with the pitcher fluids of three Nepenthes (Nepenthaceae) pitcher plant species growing in the wild. Arch Microbiol. 2014;196:709-17.

14. Takeuchi Y, Chaffron S, Salcher MM, Shimizu-Inatsugi R, Kobayashi MJ, Diway $B$, et al. Bacterial diversity and composition in the fluid of pitcher plants of the genus Nepenthes. Syst Appl Microbiol. 2015:38:330-339.

15. Buch F, Rott M, Rottloff S, Paetz C, Hilke I, Raessler M, Mithöfer A. Secreted pitfall-trap fluid of carnivorous Nepenthes plants is unsuitable for microbial growth. Ann Bot. 2013;111:375-83.

16. Eilenberg H, Pnini-Cohen S, Schuster S, Movtchan A, Zilberstein A. Isolation and characterization of chitinase genes from pitchers of the carnivorous plant Nepenthes khasiana. J Exp Bot. 2006:57:2775-84.

17. Eilenberg H, Pnini-Cohen S, Rahamim Y, Sionov E, Segal E, Carmeli S, et al. Induced production of antifungal naphthoquinones in the pitchers of the carnivorous plant Nepenthes khasiana. J Exp Bot. 2010;61:911-22.

18. Grabherr MG, Haas BJ, Yassour M, Levin JZ, Thompson DA, Amit I, et al. Trinity: reconstructing a full-length transcriptome without a genome from RNA-Seq data. Nat. Biotechnol. 2011;29:644-52.

19. Haas BJ, Papanicolaou A, Yassour M, Grabherr M, Blood PD, Bowden J, et al. De novo transcript sequence reconstruction from RNA-seq using the trinity platform for reference generation and analysis. Nat Protoc. 2013:8:1494-512.

20. Altschul SF, Gish W, Miller W, Myers EW, Lipman DJ. Basic local alignment search tool. J Mol Biol. 1990;215:403-10.

21. Langmead B, Trapnell C, Pop M, Salzberg SL. Ultrafast and memory-efficient alignment of short DNA sequences to the human genome. Genome Biol. 2009;10:R25

22. Anders S, Huber W. Differential expression analysis for sequence count data. Genome Biol. 2010;11:R106.

23. Lohse M, Nagel A, Herter T, May P, Schroda M, Zrenner R, et al. Mercator: a fast and simple web server for genome scale functional annotation of plant sequence data. Plant Cell Environ. 2014:37:1250-8.

24. Usadel B, Nagel A, Steinhauser D, Gibon Y, Bläsing $O E$, Redestig $H$, et al. PageMan: an interactive ontology tool to generate, display, and annotate overview graphs for profiling experiments. BMC Bioinformatics. 2016;7:535.

25. Robins RJ, Juniper BE. The secretory cycle of Dionaea muscipula Ellis. II. Storage and the synthesis of the secretory proteins. New Phytol. 1980;86:297-311.

26. Saeed Al, Sharov V, White J, Li J, Liang W, Bhagabati N, et al. TM4: a free, open-source system for microarray data management and analysis. Biotechniques. 2003;34:374-8.

27. Muhlemann JK, Maeda H, Chang CY, San Miguel P, Baxter I, Cooper B, et al. Developmental changes in the metabolic network of snapdragon flowers. PLoS One. 2012;7:e40381.

28. Dkhar J, Pareek A. ASYMMETRIC LEAVES1 and REVOLUTA are the key regulatory genes associated with pitcher development in Nepenthes khasiana. Sci Rep. 2019;9:6318.

29. Yang M, Sack FD. The too many mouths and four lips mutations affect stomatal production in Arabidopsis. Plant Cell. 1995;7:2227-2239.

30. Kanaoka MM, Pillitteri LJ, Fujii H, Yoshida Y, Bogenschutz NL, Takabayashi J, et al. SCREAM/ICE1 and SCREAM2 specify three cell-state transitional steps leading to Arabidopsis stomatal differentiation. Plant Cell. 2008;20:1775-1785.

31. Hatano N, Hamada T. Proteome analysis of pitcher fluid of the carnivorous plant Nepenthes alata. J Proteome Res. 2008;7:809-16.

32. Athauda SB, Matsumoto K, Rajapakshe S, Kuribayashi M, Kojima M Kubomura-Yoshida N, et al. Enzymic and structural characterization of nepenthesin, a unique member of a novel subfamily of aspartic proteinases. Biochem J. 2004;381:295-306.

33. An $\mathrm{Cl}$, Fukusaki $\mathrm{E}$, Kobayashi A. Aspartic proteinases are expressed in pitchers of the carnivorous plant Nepenthes alata Blanco. Planta. 2002;214:661-7.

34. Matthews REF. A ribonuclease from Nepenthes spp. Biochim Biophys Acta. 1960;38:552-3.

35. Stephenson P, Hogan J. Cloning and characterization of a ribonuclease, a cysteine proteinase, and an aspartic proteinase from pitchers of the carnivorous plant Nepenthes ventricosa Blanco. Int J Plant Sci. 2006;167: 239-48. 
36. Nishimura E, Kawahara M, Kodaira R, Kume M, Arai N, Nishikawa J, et al. Slike ribonuclease gene expression in carnivorous plants. Planta. 2013;238: 955-67.

37. Okabe T, Iwakiri Y, Mori H, Ogawa T, Ohyama T. An S-like ribonuclease gene is used to generate a trap-leaf enzyme in the carnivorous plant Drosera adelae. FEBS Lett. 2005;579:5729-33.

38. Płachno BJ, Adamec L, Lichtscheidl IK, Peroutka M, Adlassnig W, Vrba J. Fluorescence labelling of phosphatase activity in digestive glands of carnivorous plants. Plant Biol. 2006;8:813-20.

39. Hatano N, Hamada T. Proteomic analysis of secreted protein induced by a component of prey in pitcher fluid of the carnivorous plant Nepenthes alata. J Proteome. 2012;75:4844-52.

40. Chia TF, Aung HH, Osipov AN, Goh NK, Chia LS. Carnivorous pitcher plant uses free radicals in the digestion of prey. Redox Rep. 2004;9:255-61.

41. Fukushima K, Fang X, Alvarez-Ponce D, Cai H, Carretero-Paulet L, Chen C, et al. Genome of the pitcher plant Cephalotus reveals genetic changes associated with carnivory. Nat Ecol Evol. 2017;1:59.

42. Stotz HU, Thomson JG, Wang Y. Plant defensins defense, development and application. Plant Signal Behav. 2009:4:1010-2.

43. Rottloff S, Miguel S, Biteau F, Nisse E, Hammann P, Kuhn L, et al. Proteome analysis of digestive fluids in Nepenthes pitchers. Ann Bot. 2016;117:479-95.

44. Lee L, Zhang Y, Ozar B, Sensen CW, Schriemer DC. Carnivorous nutrition in pitcher plants (Nepenthes spp.) via an unusual complement of endogenous enzymes. J Proteome Res. 2016;15:3108-17.

45. Tökés ZA, Woon WC, Chambers SM. Digestive enzymes secreted by the carnivorous plant Nepenthes macferlanei L. Planta. 1974;119:39-46.

46. Kwon SJ, Jin HC, Lee S, Nam MH, Chung JH, Kwon SI, et al. GDSL lipase-like 1 regulates systemic resistance associated with ethylene signaling in Arabidopsis. Plant J. 2009;58:235-45.

47. Flores-Sanchez IJ, Verpoorte R. Plant polyketide synthases: a fascinating group of enzymes. Plant Physiol Biochem. 2009;47:167-74.

48. Jindaprasert A, Springob K, Schmidt J, De-Eknamkul W, Kutchan TM. Pyrone polyketides synthesized by a type III polyketide synthase from Drosophyllum lusitanicum. Phytochem. 2008;69:3043-53.

49. Sota T, Mogi M, Kato K. Local and regional-scale food web structure in Nepenthes alata pitchers. Biotropica. 1998;30:82-91.

50. Lee JM, Tan WS, Ting ASY. Revealing the antimicrobial and enzymatic potentials of culturable fungal endophytes from tropical pitcher plants (Nepenthes spp.). Mycosphere. 2014;5:364-77.

51. Glenn A, Bodri MS. Fungal endophyte diversity in Sarracenia. PLoS One. 2012;7:e32980

52. Nakayan $\mathrm{P}$, Hameed A, Singh S, Young L-S, Hung M-H, Young C-C. Phosphate-solubilizing soil yeast Meyerozyma guilliermondii CC1 improves maize (Zea mays L.) productivity and minimizes requisite chemical fertilization. Plant Soil. 2013;373:301-15.

53. Guarner F, Malagelada J. Gut flora in health and disease. Lancet. 2003;361: 512-9.

54. Chan X-Y, Hong K-W, Yin W-F, Chan K-G. Microbiome and biocatalytic bacteria in monkey cup (Nepenthes pitcher) digestive fluid. Sci Rep. 2016;6:20016.

55. Thornhill AH, Harper IS, Hallam ND. The development of the digestive glands and enzymes in the pitchers of three Nepenthes species: N. alata, N. tobaica, and N. ventricosa (Nepenthaceae). Int J Plant Sci. 2008;169:615-24.

56. Takeuchi Y, Salcher MM, Ushio M, Shimizu-Inatsugi R, Kobayashi MJ, Diway B, et al. 2011. In situ enzyme activity in the dissolved and particulate fraction of the fluid from four pitcher plant species of the genus Nepenthes. PLoS One 2011;6:e25144

57. Eisen MB, Spellman PT, Brown PO, Botstein D. Cluster analysis and display of genome-wide expression patterns. Proc Natl Acad Sci U S A. 1998;95:14863-8.

58. Lin W, Shuai B, Springer PS. The Arabidopsis LATERAL ORGAN BOUNDARIES-domain gene ASYMMETRIC LEAVES2 functions in the repression of KNOX gene expression and in adaxial-abaxial patterning. Plant Cell. 2003;15:2241-52.

59. Kerstetter RA, Bollman K, Taylor RA, Bomblies K. Poethig RS. KANADI regulates organ polarity in Arabidopsis. Nature. 2011;411:706-709.

60. McConnell JR, Emery J, Eshed Y, Bao N, Bowman J, Barton MK. Role of PHABULOSA and PHAVOLUTA in determining radial patterning in shoots. Nature. 2001:411:709-13.

61. Emery JF, Floyd SK, Alvarez J, Eshed Y, Hawker NP, Izhaki A, et al. Radial patterning of Arabidopsis shoots by class III HD-ZIP and KANADI genes. Curr Biol. 2003:13:1768-74.
62. Zhong R, Ye ZH. Amphivasal vascular bundle 1, a gain-of-function mutation of the IFL1/REV gene, is associated with alterations in the polarity of leaves, stems and carpels. Plant Cell Physiol. 2004;45:369-85.

63. Bowman $\mathrm{JL}$, Eshed $\mathrm{Y}$, Baum SF. Establishment of polarity in angiosperm lateral organs. Trends Genet. 2002;18:134-41.

64. Tibshirani R, Walther $G$, Hastie T. Estimating the number of clusters in a data set via the gap statistic. J R Stat Soc B. 2001;63:411-23.

65. Juniper BE, Robins RJ, Joel DM. The carnivorous plants. London: Academic Press: 1989.

\section{Publisher's Note}

Springer Nature remains neutral with regard to jurisdictional claims in published maps and institutional affiliations.
Ready to submit your research? Choose BMC and benefit from:

- fast, convenient online submission

- thorough peer review by experienced researchers in your field

- rapid publication on acceptance

- support for research data, including large and complex data types

- gold Open Access which fosters wider collaboration and increased citations

- maximum visibility for your research: over $100 \mathrm{M}$ website views per year

At BMC, research is always in progress.

Learn more biomedcentral.com/submissions 